\title{
De novo atrial fibrillation after mitral valve surgery
}

Christopher K. Mehta, MD, Patrick M. McCarthy, MD, Adin-Cristian Andrei, PhD, Jane Kruse, BSN, Hangzhi Shi, MS, Andrei Churyla, MD, S. Chris Malaisrie, MD, Duc Thinh Pham, MD, and

James L. Cox, MD

\section{ABSTRACT}

Objectives: We sought to determine the incidence and risk factors for de novo atrial fibrillation ( $>90$ days after surgery) in patients without preoperative atrial fibrillation.

Methods: From 2004 to 2014, 2261 patients underwent mitral valve surgery; 1288 patients $(57 \%)$ did not have a history of atrial fibrillation, and 930 patients had rhythm information more than 90 days after surgery. De novo atrial fibrillation and death probabilities were estimated using a semi-competing risks, multi-state model. Univariable and multivariable risk factors for developing atrial fibrillation were identified using the Fine-Gray model.

Results: The 5- and 10-year incidences of de novo atrial fibrillation were $14 \%$ and $23 \%$, respectively. Univariable risk factors were older age, more complex operations, more tricuspid regurgitation, and congestive heart failure (all $P<.05$ ). Patients with degenerative mitral regurgitation were less likely to develop atrial fibrillation (hazard ratio [HR], 0.4; 95\% confidence interval [CI], 0.24-0.65; $P<.001$ ). Multivariable risk factors for de novo atrial fibrillation were tricuspid valve surgery (HR, $1.80 ; 95 \%$ CI, 1.22, 2.65; $P=.003)$, aortic valve surgery $(\mathrm{HR}, 1.49$; $95 \% \mathrm{CI}, 1.03$ $2.17 ; P=.035)$, and older age (HR, $1.03 ; 95 \% \mathrm{CI}, 1.02-1.05 ; P<.001)$. De novo atrial fibrillation did not affect overall survival $(P=.41)$. Among patients who developed de novo atrial fibrillation, we observed increased use of warfarin $(P<.001)$ and a strong trend toward an increased risk of stroke $(P=.055)$.

Conclusions: De novo atrial fibrillation develops progressively after mitral surgery and is associated with a strong trend toward stroke. Patients at high risk could be studied in a trial to reduce atrial fibrillation. ( $\mathrm{J}$ Thorac Cardiovasc Surg 2018;156:1515-25)

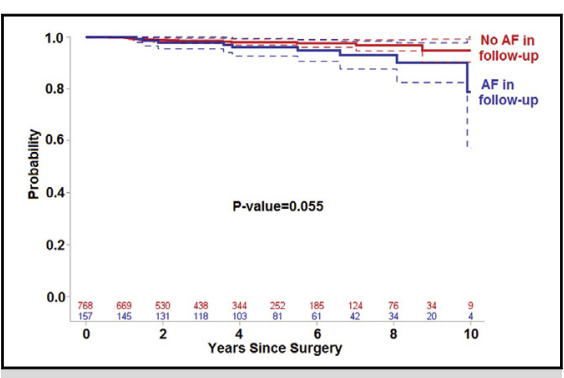

Freedom from stroke by AF status in follow-up.

\section{Central Message}

A steady rate of de novo $\mathrm{AF}(>90$ days postsurgery) develops after MV surgery in patients without a preoperative history of $\mathrm{AF}$ and was associated with a trend $(P=.055)$ toward increased stroke.

\section{Perspective}

Development of de novo AF after MV surgery may affect the risk of stroke and development of functional TR. Identifying patients at risk of developing $\mathrm{AF}$ and treating them with prophylactic ablation may reduce the risk of $\mathrm{AF}$ lower stroke risk, and limit late functional TR

See Editorial Commentary page 1526

See Editorial page 1514.
Preoperative atrial fibrillation (AF) in patients undergoing surgery for mitral valve (MV) disease is associated with late adverse events and reduced survival. ${ }^{1,2}$ When

\footnotetext{
From the Division of Cardiac Surgery, Department of Surgery, Northwestern University Feinberg School of Medicine and Northwestern Medicine, Bluhm Cardiovascular Institute, Chicago, Ill

Institutional Review Board Approval: Northwestern University approved STU00012288

Read at the 43rd Annual Meeting of The Western Thoracic Surgical Association, Colorado Springs, Colorado, June 21-24, 2017.

Received for publication June 21, 2017; revisions received Feb 23, 2018; accepted for publication April 10, 2018.

Address for reprints: Patrick M. McCarthy, MD, Division of Cardiac Surgery, Northwestern University Feinberg School of Medicine and Northwestern Memorial Hospital, Bluhm Cardiovascular Institute, 201 E Huron St, Suite 11-140, Chicago, IL 60611 (E-mail: pmccart@nm.org).

$0022-5223 / \$ 36.00$

Copyright (c) 2018 by The American Association for Thoracic Surgery

https://doi.org/10.1016/j.jtcvs.2018.04.050
}

$\mathrm{AF}$ is identified preoperatively, surgical ablation is recommended to attempt sinus rhythm restoration. ${ }^{3,4}$ Multiple prospective randomized studies have demonstrated that the addition of surgical ablation to MV surgery for patients with preoperative AF significantly increases freedom from $\mathrm{AF}^{3,5}$ The addition of a surgical ablation procedure does not increase morbidity or mortality and has even been associated with better perioperative outcomes. ${ }^{6}$

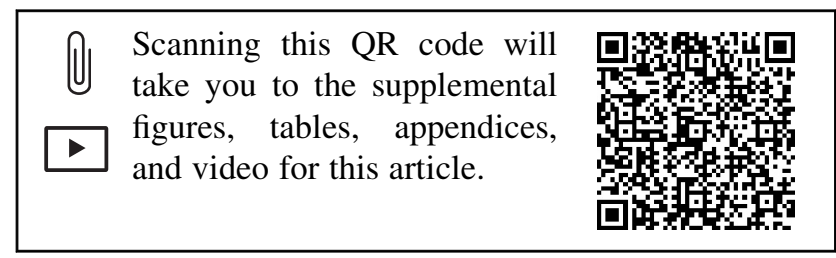




$$
\begin{aligned}
& \text { Abbreviations and Acronyms } \\
& \text { AF }=\text { atrial fibrillation } \\
& \text { AV }=\text { aortic valve } \\
& \text { CARD }=\text { Cardiovascular Research Database } \\
& \text { CI } \quad=\text { confidence interval } \\
& \text { DMR }=\text { degenerative mitral regurgitation } \\
& \text { HR } \quad=\text { hazard ratio } \\
& \text { MV } \quad \text { mitral valve } \\
& \text { PS }=\text { propensity score } \\
& \text { TR } \quad \text { tricuspid regurgitation } \\
& \text { TV } \quad \text { tricuspid valve }
\end{aligned}
$$

De novo AF, defined in this study as new AF 90 days or more after MV surgery (to exclude patients with only early postoperative $\mathrm{AF}$ ), has been infrequently studied, and there are little data on incidence and risk factors for this. ${ }^{7}$ We therefore sought to (1) characterize the incidence over time of de novo AF in patients who underwent MV surgery with or without additional cardiac surgical procedures; (2) identify potentially modifiable preoperative or perioperative risk factors for de novo AF, such that a prophylactic AF ablation procedure might be considered; and (3) evaluate the sample size of a potential study designed to reduce the incidence of de novo $\mathrm{AF}$ (Video 1).

\section{MATERIALS AND METHODS Patients}

From April 2004 to December 2014, 2261 patients had mitral \pm other cardiac procedures, and of these, 1370 had no AF history and therefore no surgical AF ablation. A preoperative Holter monitor was routinely obtained in any patient with symptoms suggestive of arrhythmias to confirm absence of AF. After excluding patients who refused to participate in the Bluhm Cardiovascular Institute's Clinical Trials Unit Cardiovascular Research Database (CARD) at Northwestern University (IRB\#STU00012288), 1288 patients (94\%) were included. Of those, $930(72 \%)$ had follow-up heart rhythm information at 90 days or more after surgery and comprise the study cohort. Preoperative, intraoperative, and postoperative data were obtained from CARD, and the Society of Thoracic Surgery database definitions were used for complications. Reported stroke includes transient ischemic attack and cerebrovascular accident (hemorrhagic or ischemic). Postoperative AF includes patients with new AF or atrial flutter persisting longer than 1 hour or requiring treatment before discharge per Society of Thoracic Surgeons definitions.

\section{Atrial Fibrillation Monitoring and Clinical Follow-up Protocols}

Unlike Northwestern patients treated with AF ablation who undergo a regimen of postoperative AF monitoring, ${ }^{8}$ these patients were not routinely monitored. Test results and office visits were prospectively collected by patient surveys at 6 and 12 months postdischarge and annually thereafter. Records pertaining to reported office visits, echocardiography and rhythm information, operations, cardioversions, catheter ablation, or hospitalizations were obtained and analyzed. Mortality data were aggregated continuously consulting sources that included (1) CARD registry; (2) reviews of medical records and correspondence with the treating physician; (3) online death indexes, including the Social Security Death Index and genealogy resources (ancestry.com); and (4) newspaper death notices. With the use of these sources, mortality follow-up information was available on $100 \%$ of the cohort.

\section{Statistical Analyses}

Data summaries included the mean and standard deviation or median and interquartile range for continuously distributed variables, such as age and left ventricular ejection faction. For discrete or categoric variables, such as gender or postsurgical complications, we have reported counts and percentages. Comparisons between patients who developed de novo AF during follow-up and those who did not were based on the 2-sample $t$ test with unequal variances and Satterthwaite's approximation or the Wilcoxon rank-sum test for continuous variables. Comparisons involving discrete or categoric variables were based on the chi-square or Fisher exact test (when cell counts were $<5$ ).

To estimate the probabilities of de novo AF, death, or AF-free survival, we used a 3-state Markov model that relies on the Aalen-Johansen estimator, as implemented in the R package etm. ${ }^{9}$ Comparisons between patients with and without de novo AF were made at 1, 2, 3, 5, and 10 years after the index surgical procedure, both in the entire cohort and separately for those with degenerative mitral regurgitation (DMR), rheumatic, and ischemic MV cause, as well as the group with mixed causes or otherwise hard to classify that were grouped together as "other." Overall survival was estimated using the Kaplan-Meier estimator.

To identify univariable or multivariable risk factors for de novo AF during follow-up, the subdistribution functions were modeled using the Fine-Gray model implemented in the R package survival. ${ }^{10} \mathrm{We}$ report (sub) hazard ratios and corresponding $95 \%$ confidence intervals (Table E1). To assess whether postoperative AF was associated with a higher risk of de novo AF during follow-up or with overall survival, we have used 1-to-1 propensity score (PS) matching. A total of 32 variables (included in the online Appendix, Table E2, and Figure E1), including demographics (age, body mass index), medical history, preoperative medications, and concomitant procedures (aortic valve [AV], TV surgery) were used to create the PS model of which the outcome was postoperative AF. A caliper of size 0.1 logit-PS standard deviation units was used. Association between TV surgery and risk of de novo AF was assessed using a 2-to-1 PS-matched analysis with a size 0.2 logit-PS standard deviation units caliper (Table E3 and Figure E2). Additional information is provided in the Appendix (Tables E4 and E5, Figures E3 and E4).

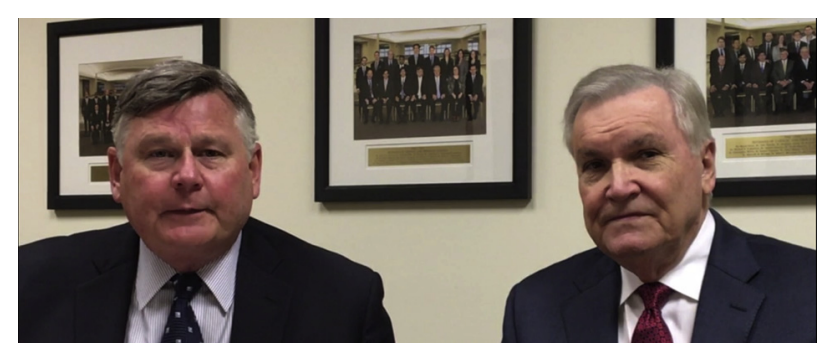

VIDEO 1. Dr Patrick M. McCarthy and Dr James L. Cox discuss aspects of the article. Video available at: https://www.jtcvs.org/article/S00225223(18)31035-3/fulltext. 
TABLE 1. Baseline characteristics of patients by de novo atrial fibrillation status in follow-up

\begin{tabular}{|c|c|c|c|c|}
\hline Variable & Entire cohort $(N=930)$ & No AF in follow-up $(\mathrm{N}=773)$ & AF in follow-up $(N=157)$ & $P$ value \\
\hline Age & $59.9 \pm 13.9$ & $58.7 \pm 13.8$ & $65.4 \pm 13.0$ & $<.001$ \\
\hline $\mathrm{CHA}_{2} \mathrm{DS}_{2}$-VASc & $2.3 \pm 1.8$ & $2.2 \pm 1.8$ & $2.9 \pm 1.7$ & $<.001$ \\
\hline Ejection fraction & $60.0(53.0,65.0)$ & $60.0(55.0,65.0)$ & $60.0(45.0,63.0)$ & .004 \\
\hline Left atrial size $(\mathrm{cm})(\mathrm{N}=866)$ & $4.3(3.8,4.7)$ & $4.3(3.8,4.7)$ & $4.3(3.8,4.9)$ & .28 \\
\hline Female & $392(42)$ & $324(42)$ & $68(43)$ & .75 \\
\hline Diabetes & $126(14)$ & $97(13)$ & $29(18)$ & .048 \\
\hline Hypertension & $518(56)$ & $421(54)$ & $97(62)$ & .09 \\
\hline Prior coronary artery bypass & $50(5)$ & $36(5)$ & $14(9)$ & .031 \\
\hline Prior pacemaker & $27(3)$ & $17(2)$ & $10(6)$ & .005 \\
\hline Congestive heart failure & $312(34)$ & $247(32)$ & $65(41)$ & .022 \\
\hline Coronary artery disease & $302(34)$ & $233(31)$ & $69(45)$ & .001 \\
\hline Repeat sternotomy & $105(11)$ & $79(10)$ & $26(17)$ & .022 \\
\hline Aortic stenosis & $103(14)$ & $75(12)$ & $28(20)$ & .023 \\
\hline Mitral stenosis & $92(11)$ & $68(10)$ & $24(17)$ & .008 \\
\hline New York Heart Association class & & & & .033 \\
\hline Class I & $278(30)$ & $244(32)$ & $34(22)$ & \\
\hline Class II & 345 (38) & $280(37)$ & $65(42)$ & \\
\hline Class III & $234(25)$ & $185(24)$ & $49(31)$ & \\
\hline Class IV & $63(7)$ & $55(7)$ & $8(5)$ & \\
\hline $\mathrm{TR}>2+$ & $165(18)$ & $128(17)$ & $37(25)$ & .024 \\
\hline MV cause & & & & $<.001$ \\
\hline Degenerative & $479(52 \%)$ & $424(55 \%)$ & $55(35 \%)$ & \\
\hline Ischemic & $90(10 \%)$ & $64(8 \%)$ & $26(17 \%)$ & \\
\hline Rheumatic & $51(5 \%)$ & $43(6 \%)$ & $8(5 \%)$ & \\
\hline Other & $310(33 \%)$ & $242(31 \%)$ & $68(43 \%)$ & \\
\hline
\end{tabular}

Values are mean \pm standard deviation; $\mathrm{n}(\%)$; or median (first quartile, third quartile). $A F$, Atrial fibrillation; $\mathrm{CHA}_{2} D S_{2}-V A S c$, congestive heart failure, hypertension, age, diabetes, stroke, vascular disease; $T R$, tricuspid regurgitation; $M V$, mitral valve.

By using methods for binomial proportions, we have estimated the required sample size for 2 -arm randomized study designed to detect a 5-year $40 \%$ reduction of $\mathrm{AF}$ (from $13.6 \%$ to $8.2 \%$ ) with $80 \%$ power at 2-sided $5 \% \alpha$-level. Because 406 of 930 participants $(43.7 \%)$ were at risk at 5 years, we have applied an inflation factor of 930/406 $=2.02$ to compensate for the loss to follow-up.

Statistical significance was declared as the 2-sided 5\% alpha level, and there were no adjustments for multiplicity. As such, on average, 1 in 20 associations identified might be spurious. All analyses were performed in R v. 3.1 .1 (http://cran.r-project.org) and SAS v. 9.3 (SAS Institute, Inc, Cary, NC).

\section{RESULTS}

The preoperative characteristics of study participants are summarized in Table 1. Concomitant procedures included AV surgery $(\mathrm{n}=199 ; 21 \%)$, tricuspid valve (TV) surgery $(\mathrm{n}=118 ; 13 \%)$, and coronary artery bypass grafting $(\mathrm{n}=248 ; 27 \%)$. MV disease cause distribution was DMR $(\mathrm{n}=479 ; 52 \%)$, rheumatic $(\mathrm{n}=51 ; 5 \%)$, ischemic $(\mathrm{n}=90 ; 10 \%)$, and "other" $(\mathrm{n}=310 ; 33 \%)$.
MV disease was treated by repair $(\mathrm{n}=728 ; 78 \%)$ or replacement $(\mathrm{n}=202 ; 22 \%)$. Rhythm assessment was based on 1 or more sources: electrocardiogram (881; $95 \%)$; Holter monitor $(176 ; 19 \%)$; implantable pacemaker or loop recorder $(130 ; 14 \%)$; outpatient telemetry $(97$; $10 \%)$; cardiac rehabilitation $(59 ; 6 \%)$; or other $(59 ; 6 \%)$. The mean follow-up time was $4.6 \pm 3.0$ years (median, 4.4; interquartile range, 1.9-7.0; maximum, 11.1 years).

Of the 930 patients, $157(17 \%)$ developed de novo AF. They were significantly older at the time of index surgery $(65 \pm 13$ years vs $59 \pm 14$ years, $P<.001)$, had more comorbidities, and underwent more complex surgeries (prior coronary artery bypass $[9 \%$ vs $5 \%, P=.031]$, prior pacemaker implantation $[6 \%$ vs $2 \%, P=.005]$, congestive heart failure $[41 \%$ vs $32 \%, P=.022]$, and coronary artery disease $[45 \%$ vs $31 \%, P=.001]$ ) than patients who were AF-free during follow-up. In addition, patients with de novo AF underwent more concomitant procedures than those without de novo AF, including 
TABLE 2. Operative, predischarge, and postoperative characteristics by de novo atrial fibrillation status in follow-up

\begin{tabular}{|c|c|c|c|c|}
\hline Variable & $\begin{array}{l}\text { Entire cohort } \\
\qquad(\mathbf{N}=930)\end{array}$ & $\begin{array}{l}\text { No AF in follow-up } \\
\qquad(N=773)\end{array}$ & $\begin{array}{l}\text { AF in follow-up } \\
\quad(N=157)\end{array}$ & $P$ value \\
\hline Perfusion time (min) & $98.5(76.0,135.0)$ & $96.0(75.0,134.0)$ & $115.0(82.0,152.0)$ & $<.001$ \\
\hline Crossclamp time (min) & $80.0(63.0,110.0)$ & $79.0(62.0,108.0)$ & $89.0(68.0,121.0)$ & .008 \\
\hline Coronary artery bypass & $248(27 \%)$ & $190(25 \%)$ & $58(37 \%)$ & .001 \\
\hline AV surgery & $199(21 \%)$ & $150(19 \%)$ & $49(31 \%)$ & .001 \\
\hline TV surgery & $118(13 \%)$ & $82(11 \%)$ & $36(23 \%)$ & $<.001$ \\
\hline $\begin{array}{l}\text { Mitral surgery } \\
\text { Repair } \\
\text { Replacement }\end{array}$ & $\begin{array}{l}728(78 \%) \\
202(22 \%)\end{array}$ & $\begin{array}{l}617(80 \%) \\
156(20 \%)\end{array}$ & $\begin{array}{r}111(71 \%) \\
46(29 \%)\end{array}$ & .012 \\
\hline Total intensive care unit, $\mathrm{h}$ & $31.0(24.3,68.8)$ & $30.5(24.2,66.9)$ & $44.3(26.0,72.3)$ & .038 \\
\hline Total length of stay (d) & $6.0(5.0,9.0)$ & $6.0(5.0,9.0)$ & $7.0(6.0,11.0)$ & $<.001$ \\
\hline Predischarge pacemaker & $43(5 \%)$ & $27(3 \%)$ & $16(10 \%)$ & $<.001$ \\
\hline Postoperative AF & $291(31 \%)$ & $214(28 \%)$ & $77(49 \%)$ & $<.001$ \\
\hline Discharged on antiarrhythmics & $241(26 \%)$ & $177(23 \%)$ & $64(41 \%)$ & $<.001$ \\
\hline Readmission within $30 \mathrm{~d}$ & $97(10 \%)$ & $70(9 \%)$ & $27(17 \%)$ & .003 \\
\hline Most recent postoperative $\mathrm{TR}(\mathrm{N}=879)$ & & & & $<.001$ \\
\hline None/trivial & $383(44 \%)$ & $330(45 \%)$ & $53(36 \%)$ & \\
\hline Mild & $351(40 \%)$ & $301(41 \%)$ & $50(34 \%)$ & \\
\hline Moderate & $115(13 \%)$ & $83(11 \%)$ & $32(22 \%)$ & \\
\hline Moderate-severe & $13(1 \%)$ & $9(1 \%)$ & $4(3 \%)$ & \\
\hline Severe & $17(2 \%)$ & $10(1 \%)$ & $7(5 \%)$ & \\
\hline TR $\geq 3-4+$ anytime in follow-up $(\mathrm{N}=879)$ & $48(5 \%)$ & $29(4 \%)$ & $19(13 \%)$ & $<.001$ \\
\hline
\end{tabular}

Values are mean \pm standard deviation; $\mathrm{n}(\%)$; or median (first quartile, third quartile). $A F$, Atrial fibrillation; $A V$, aortic valve; $T V$, tricuspid valve; $T R$, tricuspid regurgitation.

coronary artery bypass $(37 \%$ vs $25 \%, P=.001)$, AV surgery $(31 \%$ vs $19 \%, P=.001)$, and TV surgery $(23 \%$ vs $11 \%, P<.001)$. The de novo AF group had significantly longer median perfusion and crossclamp times (Table 2), and the incidence of predischarge pacemaker implantation was higher $(10 \%$ vs $3 \%$, $P<.001$ ). Total median length of stay was longer (7 vs 6 days, $P<.001)$, and the incidences of anticoagulant events $(3 \%$ vs $0 \%, P=.001)$, antiarrhythmics on discharge $(41 \%$ vs $23 \%, P<.001)$, and 30-day readmissions $(17 \%$ vs $9 \%, P=.003)$ were higher in the de novo AF group. Patients who developed in-hospital postoperative $\mathrm{AF}$ were more likely to develop late de novo $\mathrm{AF}(28 \%$ vs $49 \% ; P<.001)$ during follow-up.

\section{De Novo Atrial Fibrillation During Follow-up}

The incidence of de novo $\mathrm{AF} 1,5$, and 10 years after index surgery was $5.0 \%, 13.6 \%$, and $22.7 \%$, respectively (Figure 1, A). A trend toward an increased risk of stroke (Figure 2, $A$ ) was observed among patients who developed de novo $\operatorname{AF}(P=.055)$. The absolute risk of stroke was $5.8 \%$ for those who developed $\mathrm{AF}$ during follow-up and $1.7 \%$ among those who did not. The use of warfarin at last clinical follow-up was also significantly higher for patients with de novo AF $(47.1 \%$ vs $14.5 \% ; P<.001)$.

Survival was not different $(P=.41)$ among those who developed de novo AF during follow-up (Figure 2, B) and those who did not. Mortality varied depending on the underlying cause of MV disease. In the patients with DMR (Figure 3, A), mortality was $0 \%, 4.0 \%$, and $7.9 \%$ at 1,5 , and 10 years, respectively. Among patients with ischemic mitral regurgitation (Figure 3, B), mortality at 10 years was $27.9 \%$.

Among patients with rheumatic MV disease (Figure $1, B)$, the incidence of de novo $\mathrm{AF}$ was $2 \%$ during the first year, increased to $15.8 \%$ at 5 years, and reached $23 \%$ at 10 years. Among patients with DMR (Figure 3, A), the incidence of de novo AF steadily increased $(3.4 \%$ and $9.1 \%$ at 1 and 5 years, respectively) to $22.3 \% 10$ years after index surgery. For patients with ischemic MV disease (Figure 3, B), the incidence of de novo AF was initially higher than the other causes $(10.1 \%$ at 1 year, $15.1 \%$ at 5 years) but was similar by year $10(22.9 \%)$. In unadjusted analyses, the risk of de novo AF was significantly higher 


\section{Entire Cohort}

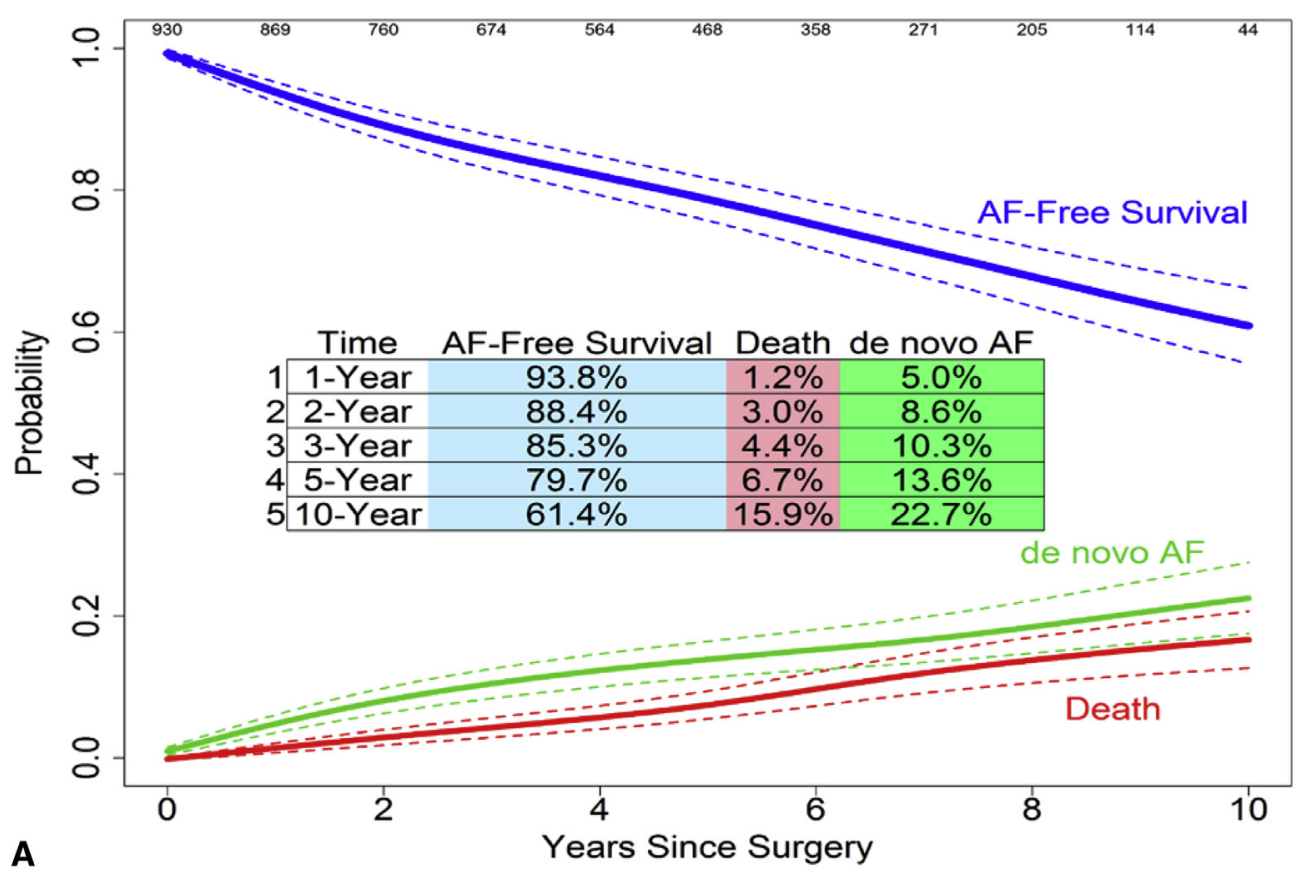

\section{Rheumatic MV Etiology}

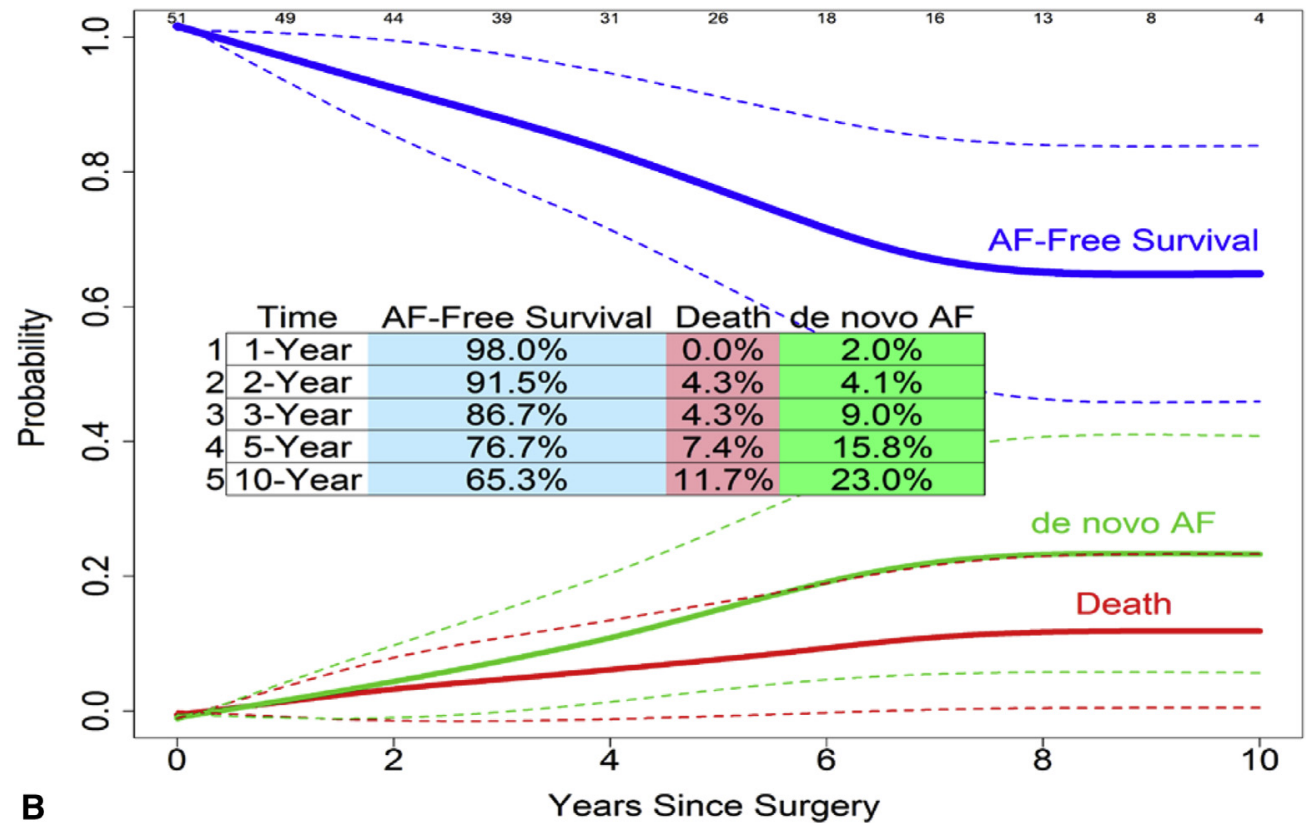

FIGURE 1. Multi-state models summary of probabilities of de novo AF, death, and AF-free survival in (A) the entire cohort $(\mathrm{N}=930)$ and $(\mathrm{B})$ rheumatic MV cause. $A F$, Atrial fibrillation; $M V$, mitral valve.

in the ischemic MV disease group compared with the DMR group (hazard ratio, 2.31; 95\% confidence interval, $1.45-3.69 ; P<.001$ ) (Table 3). After covariate adjustments, this difference was no longer significant (hazard ratio, $1.48 ; 95 \%$ confidence interval, $0.90-2.42 ; P=.12)$ (Table 4).

In PS-matched analyses, there was a trend toward an increased risk of de novo AF for patients who underwent 
Freedom-From Stroke by AF Status in Follow-Up

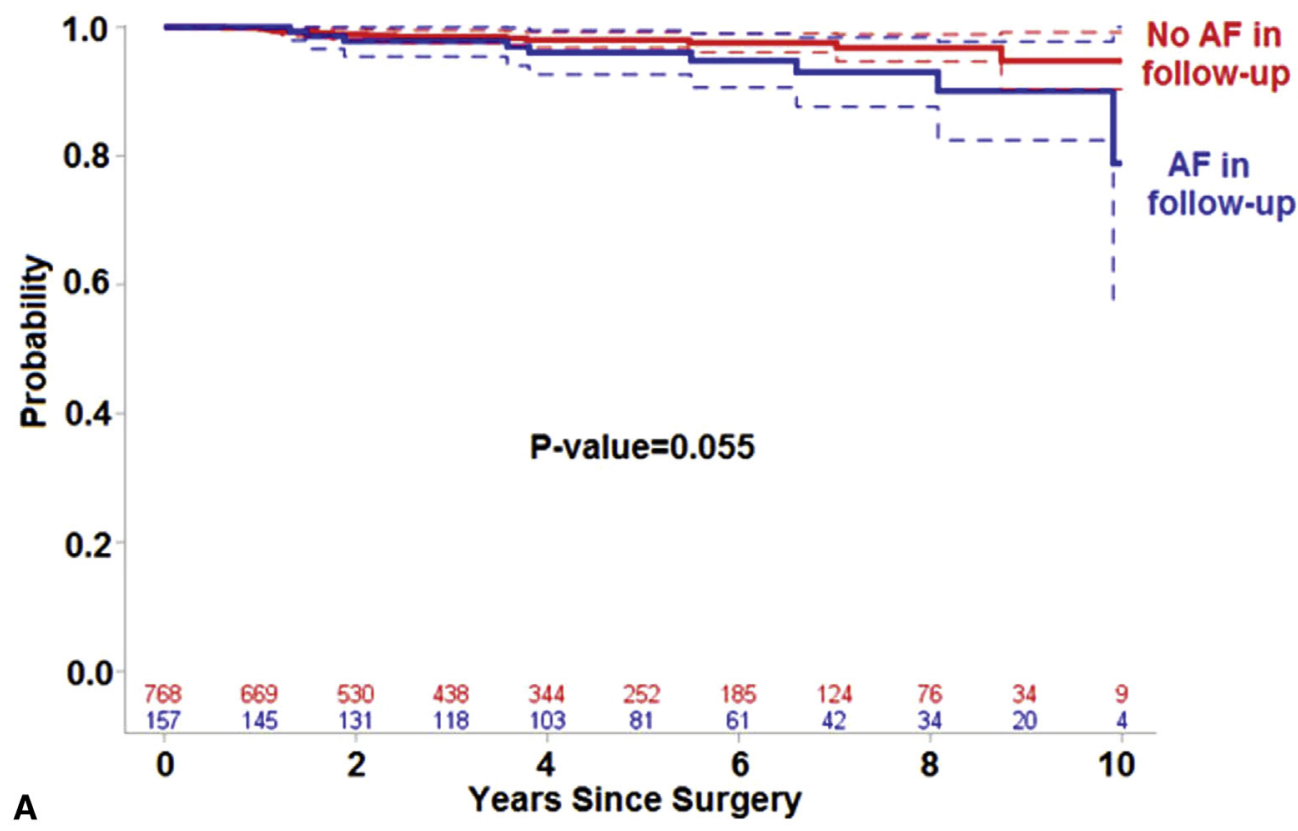

Overall Survival by AF Status in Follow-Up

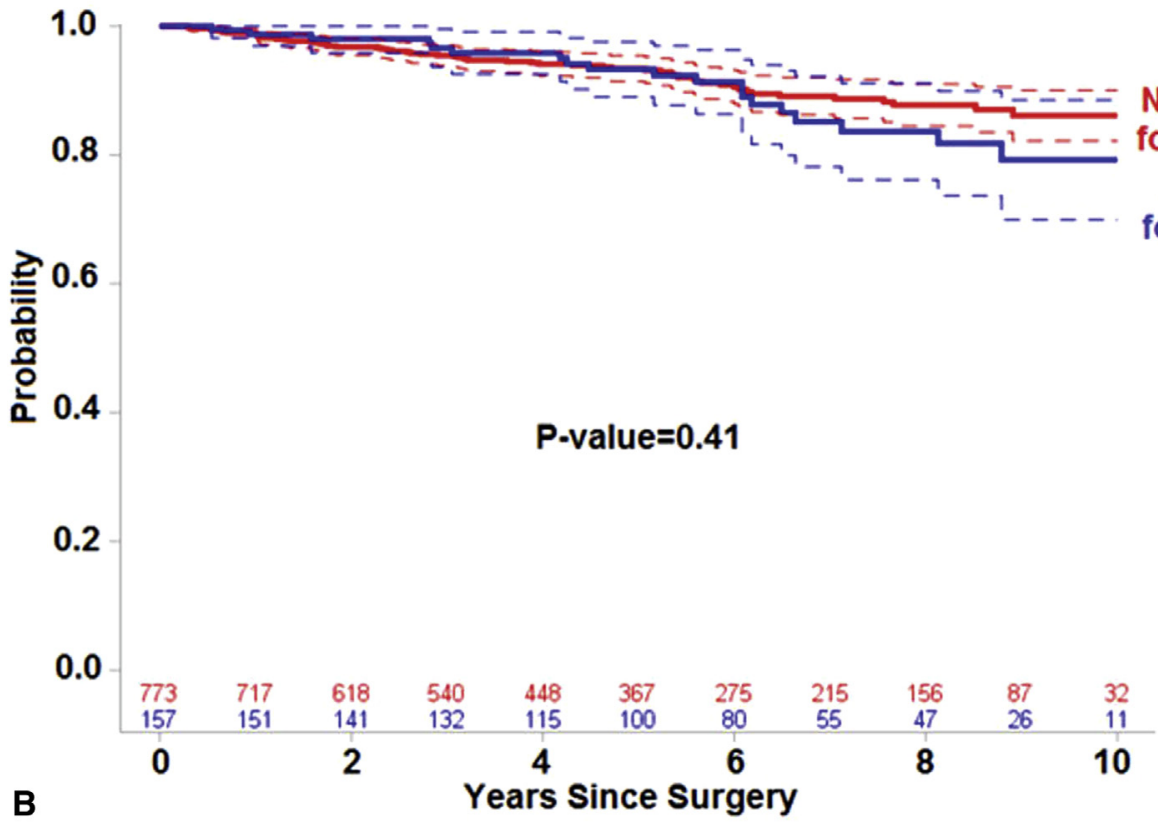

FIGURE 2. Freedom from stroke by AF status in follow-up (A) and overall survival by AF status in follow-up (B). $M V$, mitral valve; $A F$, Atrial fibrillation.

TV surgery $(P=.068)$ (Figure $4, A)$. After PS matching, patients who developed postoperative AF had a higher risk of de novo AF during follow-up $(P=.015)$ (Figure 4, B).
Tricuspid Regurgitation in Late Follow-up

Patients who developed de novo AF had more late significant tricuspid regurgitation (TR) that was severe or greater $(P<.001)$ (Table 2). 


\section{Degenerative MV Etiology}

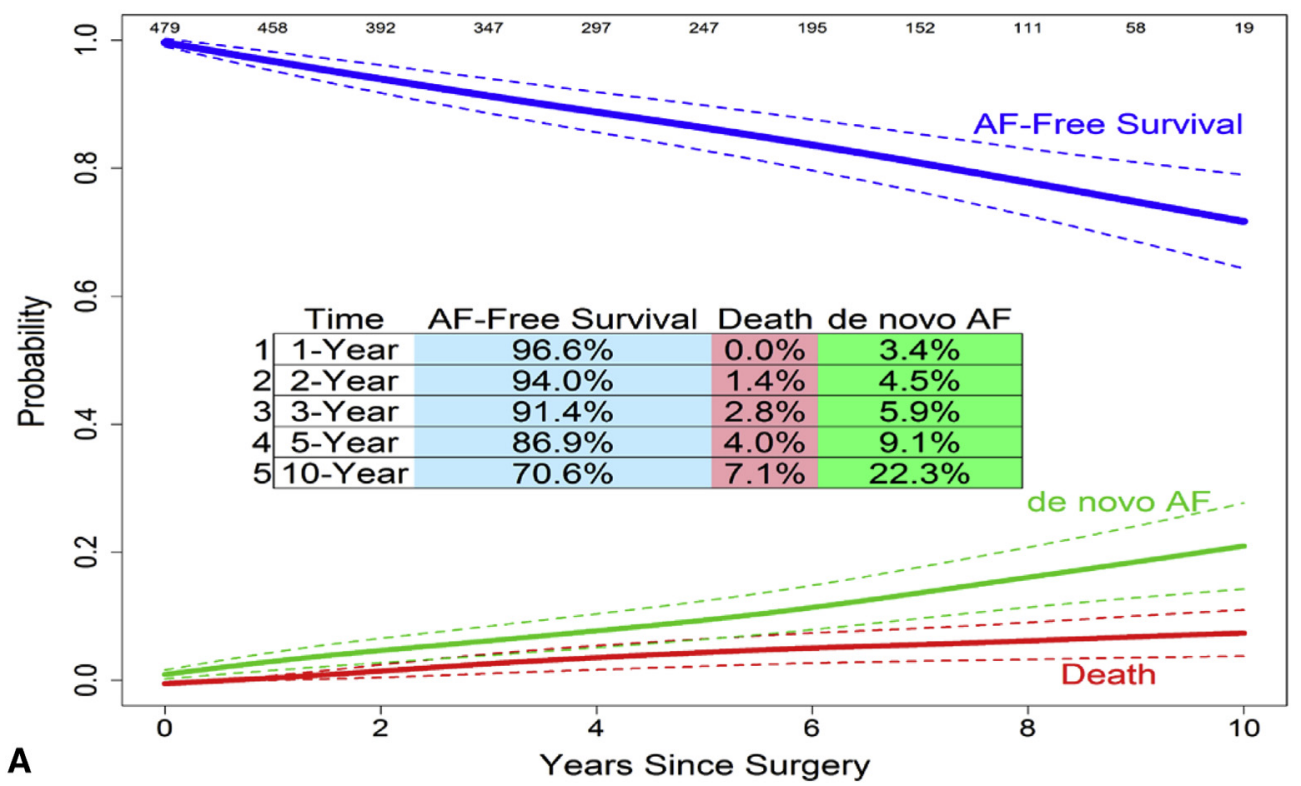

Ischemic MV Etiology

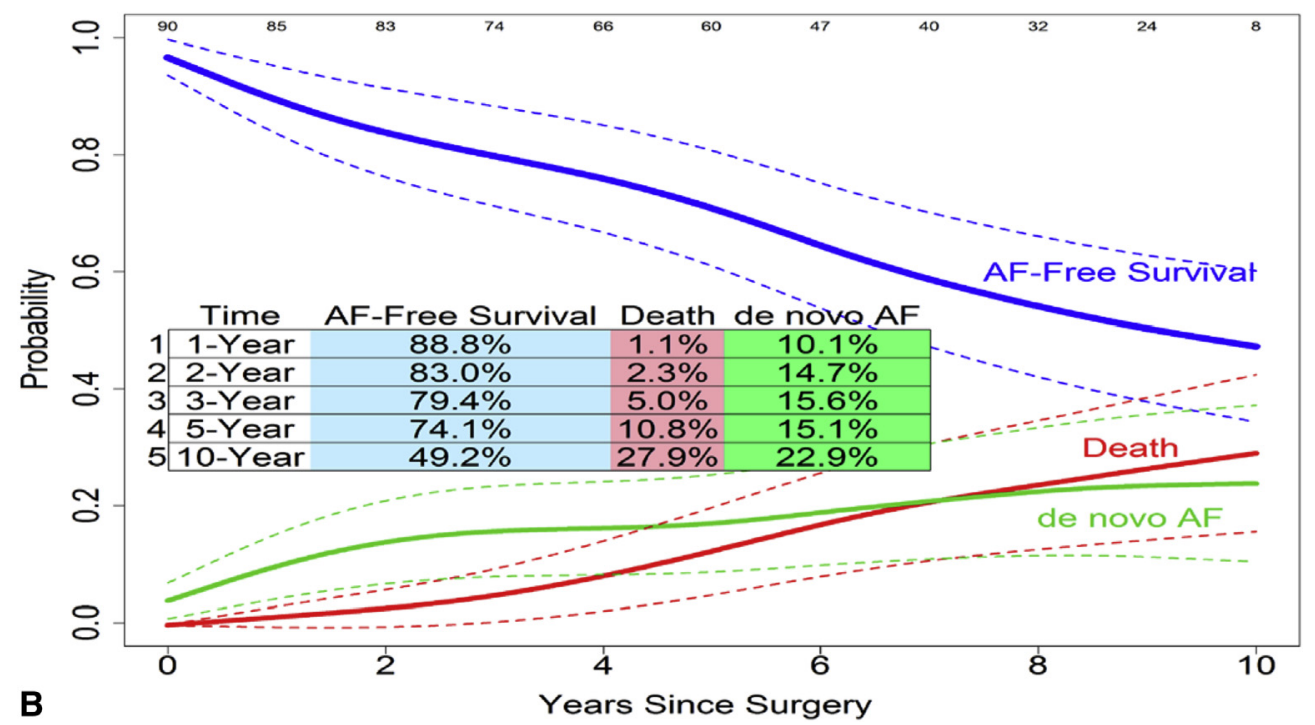

FIGURE 3. Multi-state models summary of probabilities of de novo AF, death, and AF-free survival in (A) degenerative MV cause and (B) ischemic MV cause. $A F$, Atrial fibrillation.

\section{Risk Factors for De Novo Atrial Fibrillation During Follow-up}

Preoperative and intraoperative univariable risk factors for developing de novo $\mathrm{AF}$ are displayed in Table 3. The multivariable model (Table 4) identified age at surgery $(1.03[1.02,1.05])$, TV surgery $(1.73$ $[1.17,2.56])$, and "other" cause MR versus DMR $(1.68[1.11,2.52])$ as independent risk factors for developing de novo AF. Prior pacemaker $(P=.11)$ and repeat sternotomy $(P=.28)$ were not significantly associated with an increased de novo AF risk. Left atrial size and low ejection fraction were not found to be significant risk factors for de novo $\mathrm{AF}$ (Table E1).

\section{DISCUSSION}

Summarization of AF in follow-up continues to remain challenging, despite several useful recent 
TABLE 3. Summary of significant univariate risk factors for developing de novo atrial fibrillation

\begin{tabular}{|c|c|c|c|}
\hline Variable & HR & $95 \%$ CI & $P$ value \\
\hline Age, y & 1.04 & $(1.03-1.05)$ & $<.001$ \\
\hline Diabetes & 1.60 & $(1.07-2.41)$ & .021 \\
\hline Hypercholesterolemia & 1.43 & $(1.04-1.96)$ & .027 \\
\hline Hypertension & 1.56 & $(1.13-2.16)$ & .007 \\
\hline Prior cerebrovascular accident & 1.74 & $(1.02-2.96)$ & .043 \\
\hline Prior coronary artery bypass & 1.94 & $(1.12-3.35)$ & .019 \\
\hline Prior pacemaker & 3.10 & $(1.63-5.90)$ & $<.001$ \\
\hline Congestive heart failure & 1.44 & $(1.05-1.99)$ & .024 \\
\hline Coronary artery disease & 1.79 & $(1.30-2.46)$ & $<.001$ \\
\hline Repeat sternotomy & 1.84 & $(1.21-2.81)$ & .005 \\
\hline Aortic stenosis & 1.90 & $(1.25-2.87)$ & .002 \\
\hline Mitral stenosis & 1.70 & $(1.10-2.65)$ & .018 \\
\hline Coronary artery bypass & 1.66 & $(1.20-2.30)$ & .003 \\
\hline AV surgery & 1.89 & $(1.35-2.65)$ & $<.001$ \\
\hline TV surgery & 2.34 & $(1.62-3.40)$ & $<.001$ \\
\hline MV replacement (vs repair) & 1.74 & $(1.24-2.46)$ & .002 \\
\hline \multicolumn{4}{|l|}{$\mathrm{TV}$ regurgitation } \\
\hline None/trivial & REF & REF & REF \\
\hline Mild & 1.33 & $(0.92-1.94)$ & .133 \\
\hline Moderate & 1.86 & $(1.15-3.01)$ & .011 \\
\hline Moderate/severe & 1.67 & $(0.61-4.62)$ & .319 \\
\hline Severe & 3.52 & $(1.80-6.89)$ & $<.001$ \\
\hline $\mathrm{TV}$ regurgitation $\geq 2+$ & 1.87 & $(1.29-2.72)$ & .001 \\
\hline \multicolumn{4}{|l|}{$\mathrm{CHADS}_{2}$ score } \\
\hline 0 & REF & REF & REF \\
\hline 1 & 1.98 & $(1.23-3.18)$ & .005 \\
\hline 2 & 2.78 & $(1.69-4.57)$ & $<.001$ \\
\hline 3 & 2.48 & $(1.39-4.44)$ & .002 \\
\hline 4 & 3.80 & $(1.77-8.15)$ & $<.001$ \\
\hline 5 & 4.66 & $(1.87-11.13)$ & $<.001$ \\
\hline \multicolumn{4}{|l|}{ MV cause } \\
\hline Degenerative & REF & REF & REF \\
\hline Rheumatic & 1.44 & $(0.68-3.02)$ & .34 \\
\hline Ischemic & 2.31 & $(1.45-3.69)$ & $<.001$ \\
\hline Other & 2.25 & $(1.57-3.21)$ & $<.001$ \\
\hline
\end{tabular}

$H R$, Hazard ratio; $C I$, confidence interval; $A V$, aortic valve; $T V$, tricuspid valve; $M V$, mitral valve; $\mathrm{CHADS}_{2}$, Congestive heart failure, hypertension, age, diabetes and stroke.

developments. ${ }^{11-14}$ Patients undergoing mitral surgery typically have atrial myopathy and dilated atria placing them at risk for AF. There are little data regarding how often this occurs in patients without preoperative AF. This study identified several risk factors for de novo AF, AF was not uncommon and increased over time, and there was a strong trend toward an association with late stroke. Although in our analyses, time to de novo $\mathrm{AF}$
TABLE 4. Summary of multivariable risk factors for developing de novo atrial fibrillation in follow-up

\begin{tabular}{lccc}
\hline \multicolumn{1}{c}{ Variable } & HR & $\mathbf{9 5} \% \mathbf{C I}$ & $\boldsymbol{P}$ value \\
\hline Age & 1.03 & $(1.02-1.05)$ & $<.001$ \\
Prior pacemaker & 1.75 & $(0.88-3.48)$ & .11 \\
Repeat sternotomy & 1.29 & $(0.82-2.02)$ & .28 \\
AV surgery & 1.37 & $(0.93-2.03)$ & .108 \\
TV surgery & 1.73 & $(1.17-2.56)$ & .005 \\
MV cause & & & \\
$\quad$ Degenerative & REF & REF & REF \\
Rheumatic & 0.98 & $(0.45-2.16)$ & .96 \\
Ischemic & 1.48 & $(0.90-2.42)$ & .12 \\
Other & 1.68 & $(1.11-2.52)$ & .013 \\
\hline
\end{tabular}

$H R$, Hazard ratio; $C I$, confidence interval; $A V$, aortic valve; $T V$, tricuspid valve; $M V$, mitral valve.

development is measured since surgery time, findings remain virtually unchanged if time since hospital discharge is considered instead (Figures E5-E12).

A study from The Mayo Clinic investigated 573 patients with degenerative MR over 10 years and had similar findings to ours, with $11 \%$ and $23 \%$ de novo $\mathrm{AF}$ at 5 and 10 years compared with our finding of $9.1 \%$ and $22.3 \%$, respectively. ${ }^{7}$ Risk factors for $\mathrm{AF}$ in that study were advanced age, diabetes, left atrial size greater than $50 \mathrm{~mm}$, and more than mild TR, and as in our study, TV surgery did not increase the risk of late $\mathrm{AF}$ (although in our study there was a trend in the unadjusted analysis; $P=.068$ ) (Figure 4, A). However, Stulak and colleagues $^{7}$ did find that $\mathrm{AF}$ reduced late survival $(P=.001)$, which we did not. They did not report on late stroke rate.

Unlike in the Mayo study, our cohort included patients with degenerative, rheumatic, ischemic, and other mixed-cause MV disease. The incidence of de novo AF remained similar among these 3 main groups at 10 years (degenerative $22.3 \%$, rheumatic $23 \%$, and ischemic $22.9 \%$ ) despite mortality differences. Degenerative MV disease was associated with a steady rate of de novo AF and had the lowest mortality rate among the 3 groups at 10 years $(7.1 \%)$. Patients with ischemic MV disease had a higher mortality at 10 years $(27.9 \%)$ compared with the other groups, a reflection of the poor outcome associated with this disease. The group with other causes had a higher risk for de novo AF by multivariable analysis (Table 4).

Among patients in whom de novo AF developed during follow-up, there was a trend toward an increased risk of stroke $(P=.055)$. This risk potentially could be reduced with closure of the left atrial appendage at the time of surgery; however, this is not routinely performed in the absence of a surgical ablation procedure. If one is willing 


\section{Probability of de novo AF by TV Surgery Status}

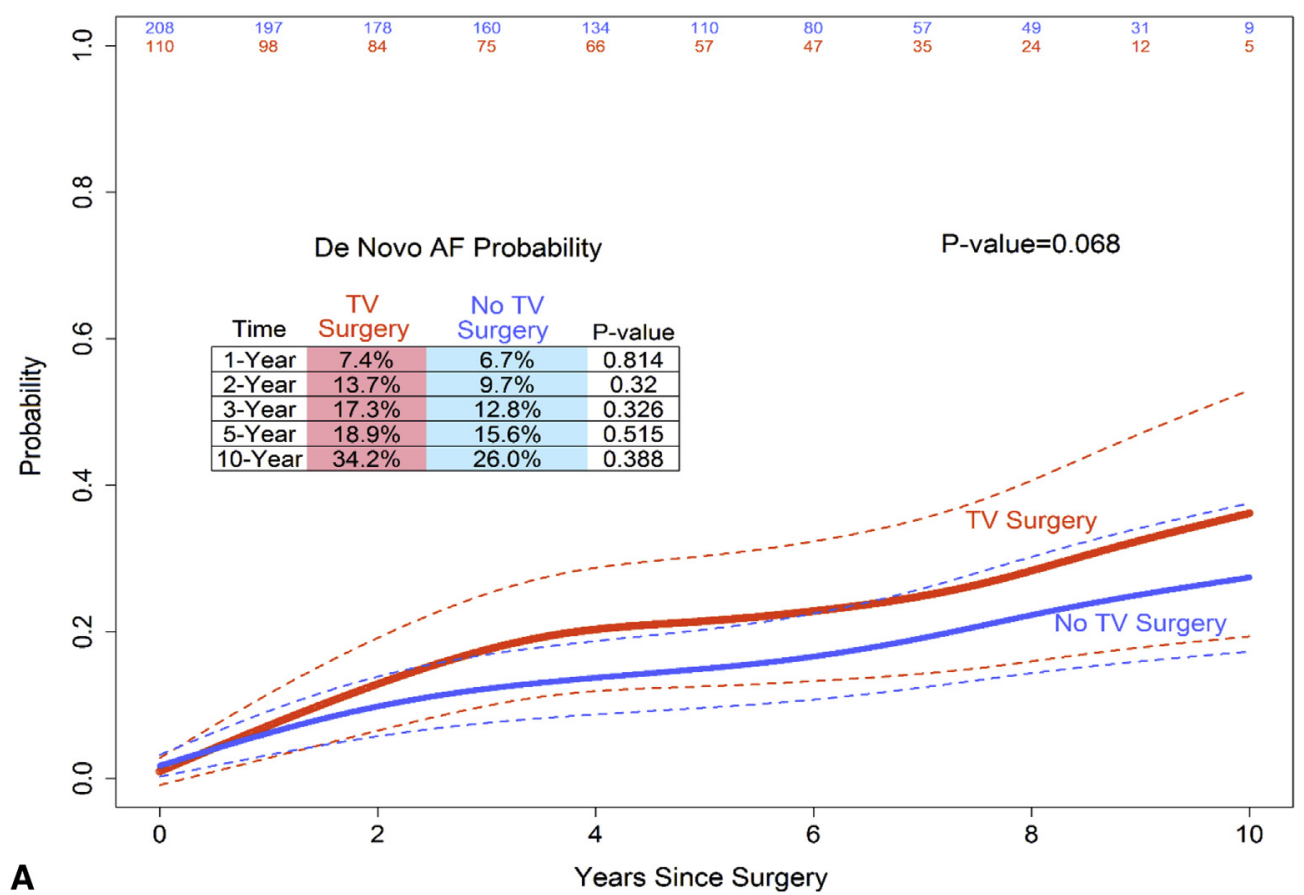

Probability of de novo AF by Post-Operative AF Status

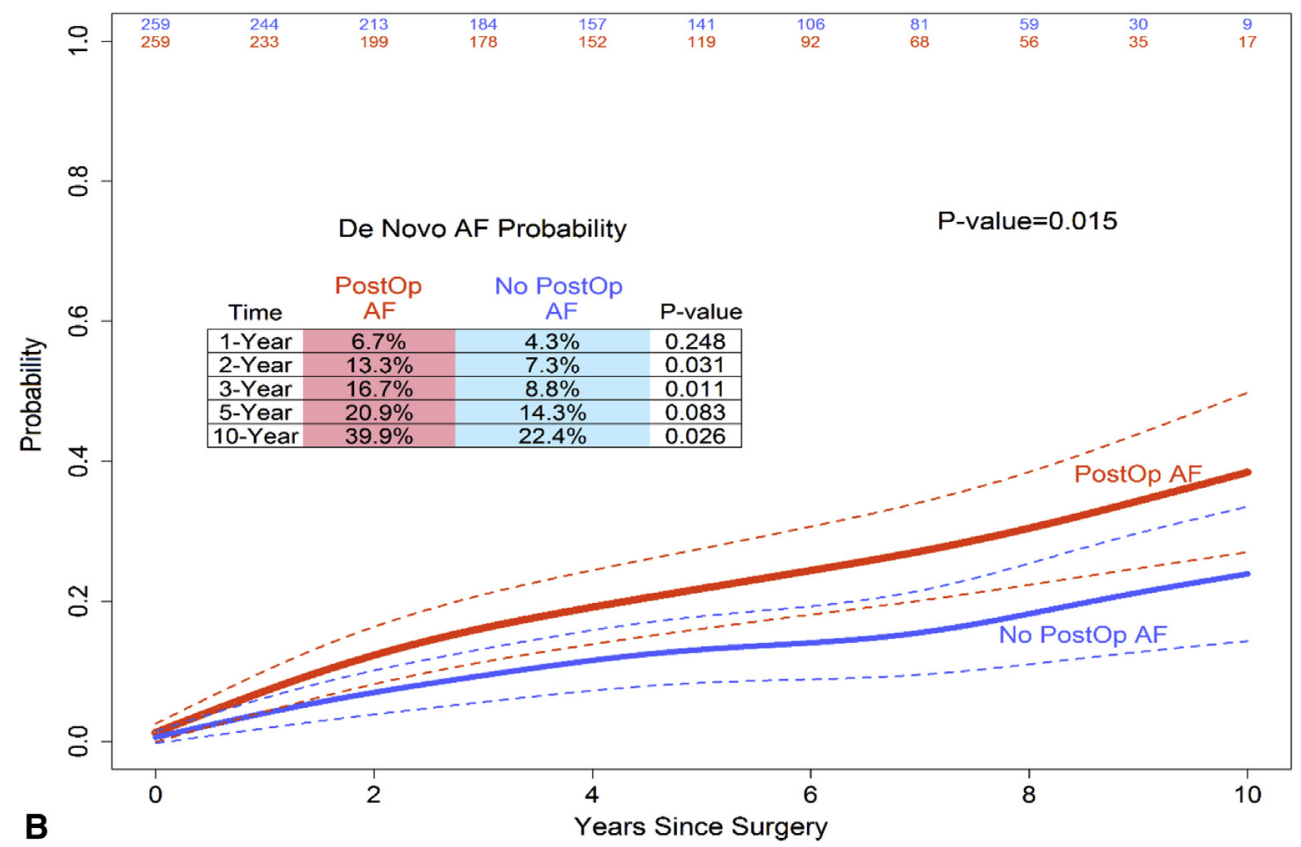

FIGURE 4. Estimated probabilities of developing de novo AF by (A) TV surgery status and (B) postoperative AF status in PS-matched groups. AF, Atrial fibrillation; $T V$, tricuspid valve.

to assume a causal relationship between $\mathrm{AF}$ and late stroke, then prophylactic treatment of AF may reduce that risk. In our cohort, overall average follow-up was in fact significantly longer among patients who developed de novo AF in follow-up than for those who did not, making selection bias unlikely: $4.96 \pm 2.90$ years (no de novo 
AF) versus $5.98 \pm 2.76$ years $($ de novo AF) $(P<.001)$. Alternative analytic approaches when selection bias is a potential concern include pattern mixture models for informative dropout. ${ }^{15}$

Our data show a univariate association between preoperative moderate or greater $\mathrm{TR}$ and the risk of de novo $\mathrm{AF}(25 \%$ if de novo $\mathrm{AF}, 17 \%$ if no de novo $\mathrm{AF}$, $P=.024)$. In addition, more patients with de novo AF had TR postoperatively. The question of whether TR leads to de novo AF or if de novo AF leads to worsening TR is an important distinction. In one study, right atrial dilation as a result of right heart volume overload in the setting of TR was shown to promote AF. ${ }^{16}$ Stulak and colleagues ${ }^{17}$ demonstrated that $\mathrm{AF}$ after MV surgery increases the risk of progression to TR and that a successful Maze procedure at the time of surgery is associated with a decrease in risk. Some patients may benefit from prophylactic AF ablation to not only limit the development of de novo AF and stroke risk but also limit late TR.

\section{A Potential Trial of Prophylactic Atrial Fibrillation Ablation}

An adequately controlled randomized trial to detect a 5 -year $40 \%$ reduction of AF with $80 \%$ power at a 2 -sided $5 \% \alpha$-level would require 2392 patients. A targeted trial of prophylactic ablation AF for high-risk patients, however, such as those aged 65 years or more with multiple valve surgery, may be more feasible.

\section{Study Limitations}

We acknowledge several limitations of our retrospective study. First, our cohort is heterogeneous because it includes patients who underwent MV surgery for a spectrum of MV diseases, with concomitant cardiac procedures, such as coronary artery bypass grafting and other valvular operations. Second, patients in our cohort had no documented evidence of preoperative AF; however, it is possible that patients had undetected past episodes of AF. Third, we identified heart rhythm information mostly via electrocardiogram. We may have underreported de novo AF because patients were not followed per protocol, such as patients treated with AF ablation. We likely reported more on patients who developed symptomatic AF and sought treatment including rhythm assessment. Patients with de novo $\mathrm{AF}$ had a higher rate of pacemaker implant predischarge that allowed a more thorough rhythm assessment. Finally, we did not have the clinical information to determine whether AF was paroxysmal, persistent, or long-standing persistent.

\section{CONCLUSIONS}

A steady rate of de novo AF ( $>90$ days postsurgery) develops after MV surgery in patients without a known preoperative history of AF. The development of de novo
AF was associated with a trend toward increased stroke risk, but not an overall survival difference. A trial of prophylactic AF ablation, especially in high-risk patients, to limit the development of late AF, stroke, and late TR may be warranted.

\section{Conflict of Interest Statement}

A.-C.A.: Atricure consultant. J.L.C.: Atricure consultant, Chairman, Scientific Advisory Board, stockholder. All other authors have nothing to disclose with regard to commercial support.

\section{References}

1. Lim E, Barlow CW, Hosseinpour AR, Wisbey C, Wilson K, Pidgeon W, et al. Influence of atrial fibrillation on outcome following mitral valve repair. Circulation. 2001;104(12 Suppl 1):I59-63.

2. Ngaage DL, Schaff HV, Mullany CJ, Barnes S, Dearani JA, Daly RC, et al. Influence of preoperative atrial fibrillation on late results of mitral repair: is concomitant ablation justified? Ann Thorac Surg. 2007;84:434-43.

3. Calkins H, Kuck KH, Cappato R, Brugada J, Camm AJ, Chen SA, et al. 2012 HRS/EHRA/ECAS expert consensus statement on catheter and surgical ablation of atrial fibrillation: recommendations for patient selection, procedural techniques, patient management and follow-up, definitions, endpoints, and research trial design: a report of the Heart Rhythm Society (HRS) task force on catheter and surgical ablation of atrial fibrillation. Developed in partnership with the European Heart Rhythm Association (EHRA), a registered branch of the European Society of Cardiology (ESC) and the European Cardiac Arrhythmia Society (ECAS); and in collaboration with the American College of Cardiology (ACC), American Heart Association (AHA), the Asia Pacific Heart Rhythm Society (APHRS), and the Society of Thoracic Surgeons (STS). Endorsed by the governing bodies of the American College of Cardiology Foundation, the American Heart Association, the European Cardiac Arrhythmia Society, the European Heart Rhythm Association, the Society of Thoracic Surgeons, the Asia Pacific Heart Rhythm Society, and the Heart Rhythm Society. Heart Rhythm. 2012;9:632-96.e621.

4. Badhwar V, Rankin JS, Damiano RJ Jr, Gillinov AM, Bakaeen FG, Edgerton JR, et al. The Society of Thoracic Surgeons 2017 clinical practice guidelines for the surgical treatment of atrial fibrillation. Ann Thorac Surg. 2017; 103:329-41

5. Gillinov AM, Gelijns AC, Parides MK, DeRose JJ Jr, Moskowitz AJ, Voisine P, et al. Surgical ablation of atrial fibrillation during mitral-valve surgery. $N$ Engl J Med. 2015;372:1399-409.

6. Rankin JS, Grau-Sepulveda MV, Ad N, Damiano RJ Jr, Gillinov AM, Brennan JM, et al. Associations between surgical ablation and operative mortality after mitral valve procedures. Ann Thorac Surg. 2018;105:1790-6.

7. Stulak JM, Suri RM, Dearani JA, Sundt TM III, Schaff HV. When should prophylactic maze procedure be considered in patients undergoing mitral valve surgery? Ann Thorac Surg. 2010;89:1395-401.

8. Churyla A, Iddriss A, Andrei AC, Kruse J, Malaisrie SC, Passman R, et al. Biatrial or left atrial lesion set for ablation during mitral surgery: risks and benefits. Ann Thorac Surg. 2017;103:1858-65.

9. Allignol A, Schumacher M, Beyersmann J. Empirical transition matrix of multi-state models: the etm package. J Stat Softw. 2011;38:1-15.

10. A package for survival analysis in $\mathrm{S}$. $\mathrm{R}$ package version $2.37-4$ [computer program]. Available at: http://CRAN.R-project.org/package=survival.

11. Andrei AC, McCarthy PM, Thomas JD, Abicht TO, Malaisrie SC, Li Z, et al. Overcoming reporting challenges: How to display, summarize, and model late reintervention outcomes, follow-up, and vital status information after surgery for atrial fibrillation. Heart Rhythm. 2015;12:1456-63.

12. Li L, Mao H, Ishwaran H, Rajeswaran J, Ehrlinger J, Blackstone EH. Estimating the prevalence of atrial fibrillation from a three-class mixture model for repeated diagnoses. Biom J. 2017;59:331-43.

13. Rajeswaran J, Blackstone EH, Ehrlinger J, Li L, Ishwaran H, Parides MK. Probability of atrial fibrillation after ablation: using a parametric nonlinear temporal decomposition mixed effects model. Stat Methods Med Res. 2018; 27:126-41. 
14. Ad N, Holmes SD, Patel J, Je HG, Shuman DJ. The need for consistent predictors of success for surgical ablation of atrial fibrillation: a call to action. Innovations. 2017; 12:421-9.

15. Little RJ. Selection and pattern-mixture models. In: Fitzmaurice G, Davidian M, Verbeke G, Molenberghs G, eds. Advances in Longitudinal Data Analysis. London: CRC Press; 2008:409-31.

16. Stulak JM, Dearani JA, Puga FJ, Zehr KJ, Schaff HV, Danielson GK. Right-sided Maze procedure for atrial tachyarrhythmias in congenital heart disease. Ann Thorac Surg. 2006;81:1780-5.
17. Stulak JM, Schaff HV, Dearani JA, Orszulak TA, Daly RC, Sundt TM III Restoration of sinus rhythm by the Maze procedure halts progression of tricuspid regurgitation after mitral surgery. Ann Thorac Surg. 2008;86: $40-5$

Key Words: mitral valve surgery, postoperative atrial fibrillation 


\section{APPENDIX}

1. Evaluation of Potential Risk Factors for Developing De Novo AF in Follow-up

In addition to the variable presented in the article's main body, we have explored several other potential risk factors for developing de novo AF. Results are shown in the following table.

\section{Additional Details Regarding the Propensity Score-Matched Analyses}

Postoperative atrial fibrillation versus no postoperative atrial fibrillation comparison. The PS model has modeled the probability of developing postoperative AF based on a logistic regression model with the following covariates: age at the time of surgery, gender, body mass index, creatinine level, left ventricular ejection fraction, diabetes, hypercholesterolemia, hypertension, chronic obstructive pulmonary disease, prior myocardial infarction, history of congestive heart failure, prior coronary artery bypass, prior heart valve procedure, repeat sternotomy, prior cardiovascular intervention, cerebrovascular disease, peripheral vascular disease, prior stroke, prior pacemaker, elective surgery, AV surgery, MV repair or replacement, coronary artery bypass grafting, New York Heart Association Functional Class III or IV, and preoperative medication (beta-blockers, anticoagulants, aspirin, statins, and diuretics).
We have modeled the probability of experiencing postoperative AF and carried out 1-to-1 PS matching with a caliper of size 0.1 logit-PS standard deviation units. The area under the receiver's operating characteristics curve was equal to 0.713 , and the Hosmer-Lemeshow test was chi-square $=6.67$, degrees of freedom $=8, P$ value $=.57$. Summaries of baseline and intraoperative characteristics after PS matching by postoperative AF status are shown in Table E2. Corresponding standardized mean differences are depicted in Figure E1. They confirm that adequate covariate balance has been achieved after PS matching.

TV surgery versus no TV surgery comparison. A similar PS-matched analysis was performed using the same variables as predictors. The caliper PS-matching process used a 2-to-1 matching ratio (no TV surgery vs TV surgery) and was based on a Greedy algorithm. A caliper of size 0.1 logit-PS standard deviation units was used. The area under the receiver's operating characteristics curve was equal to 0.753 . The Hosmer-Lemeshow test of calibration was chi-square $=6.62$, degrees of freedom $=8$, $P=$.58. Summaries of baseline and intraoperative characteristics before and after PS matching by TV surgery status are shown in Table E3. Corresponding standardized mean differences are depicted in Figure E2. They confirm that adequate covariate balance has been achieved after PS matching. 


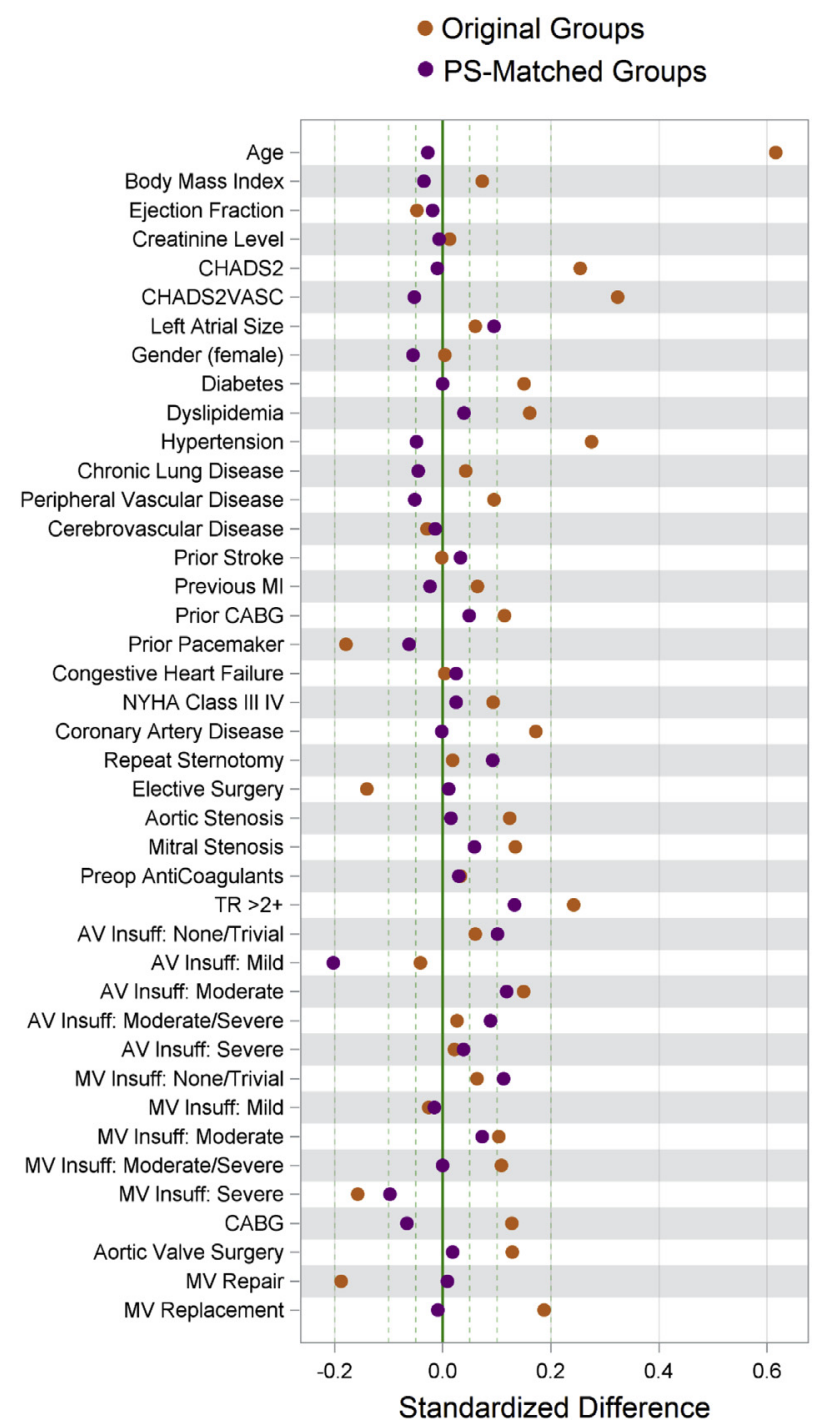

FIGURE E1. Standardized mean differences before and after PS matching by postoperative AF status. $\mathrm{PS}$, Propensity score; $\mathrm{CHADS}_{2}$, congestive heart failure, hypertension, age, diabetes, stroke; $C H A D S_{2} V A S C$, congestive heart failure, hypertension, age, diabetes, stroke, vascular disease; $M I$, myocardial infarction; $C A B G$, coronary artery bypass grafting; $N Y H A$, New York Heart Association; $T R$, tricuspid regurgitation; $A V$, aortic valve; $M V$, mitral valve.

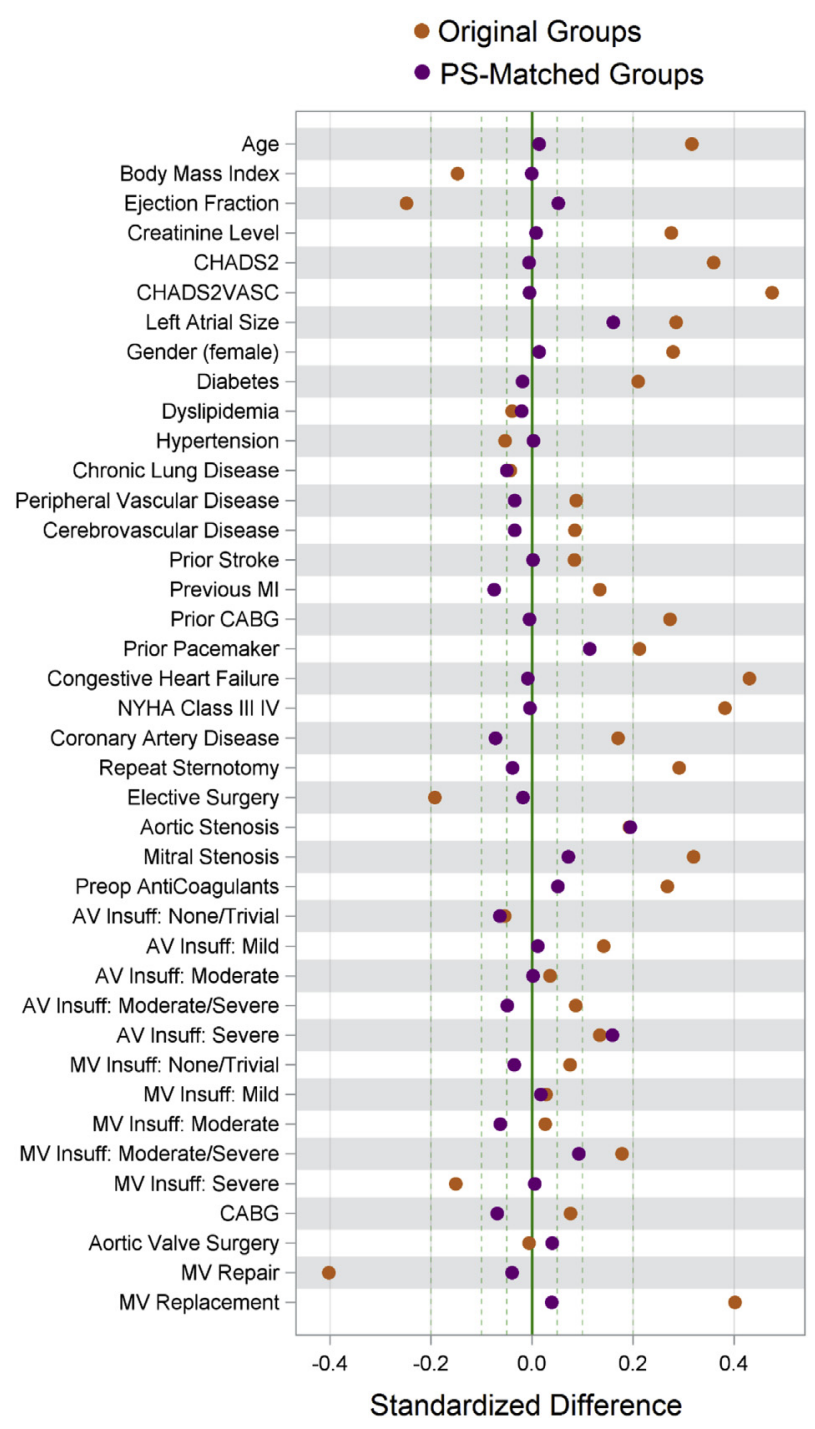

FIGURE E2. Standardized mean differences before and after PS matching by TV surgery status. $\mathrm{PS}$, Propensity score; $\mathrm{CHADS}_{2}$, congestive heart failure, hypertension, age, diabetes, stroke; $\mathrm{CHADS}_{2} V A S C$, congestive heart failure, hypertension, age, diabetes, stroke, vascular disease; $M I$, myocardial infarction; $C A B G$, coronary artery bypass grafting; NYHA, New York Heart Association; $A V$, aortic valve; $M V$, mitral valve. 


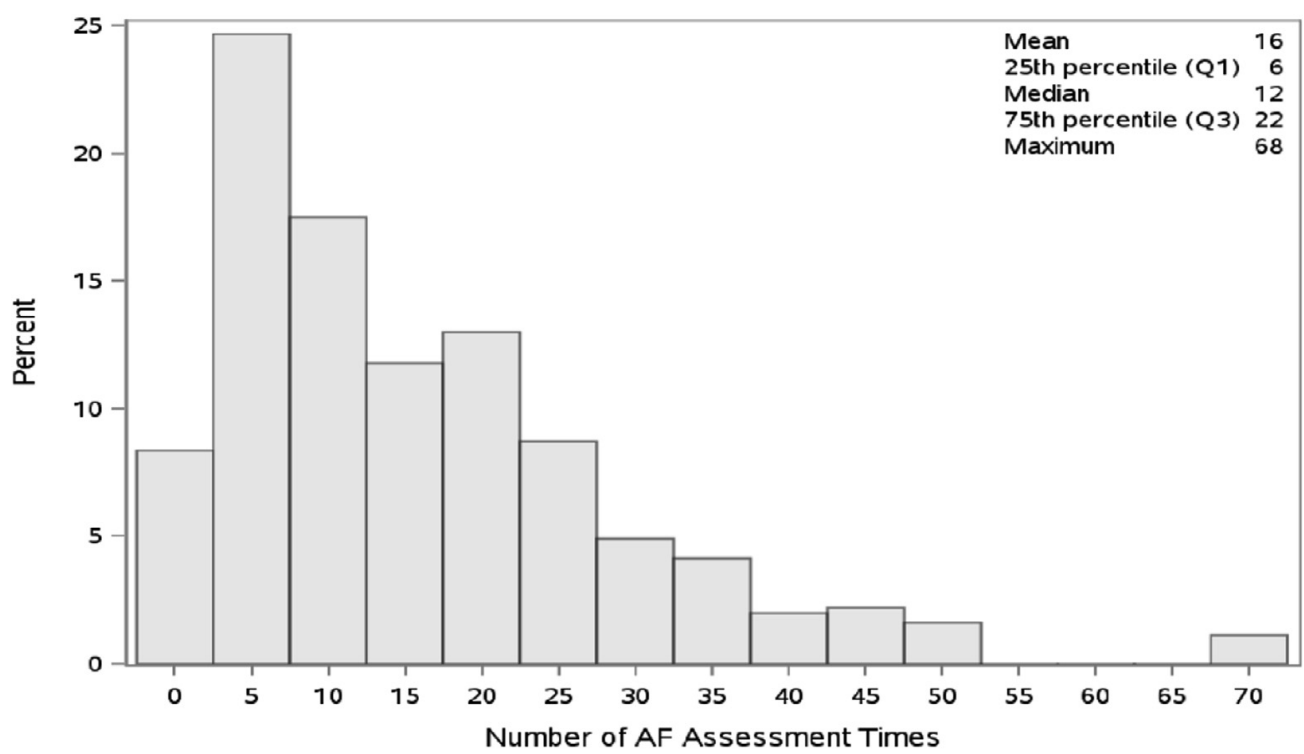

FIGURE E3. Histogram of the number of AF assessment (diagnosis) times during the postsurgical follow-up of the entire cohort. AF, Atrial fibrillation.

All Patients

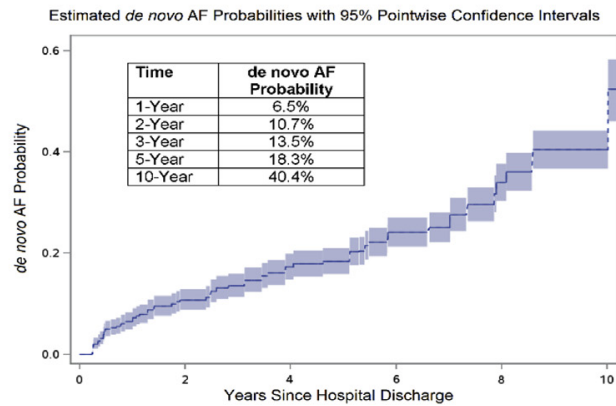

Degenerative MV Etiology

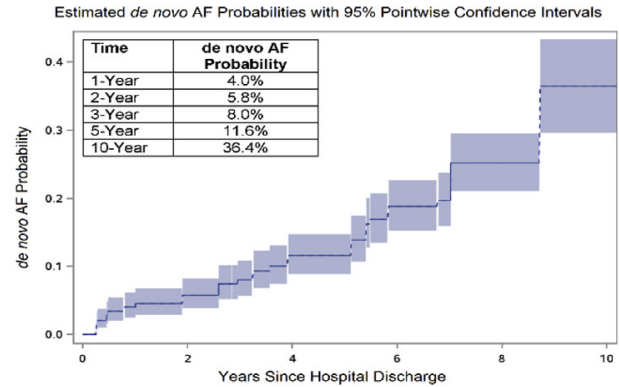

Rheumatic MV Etiology

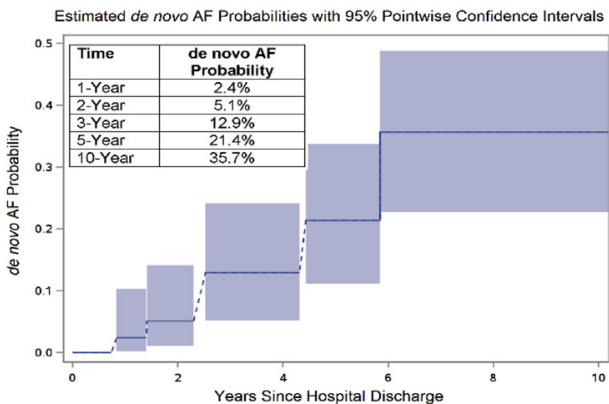

Ischemic MV Etiology

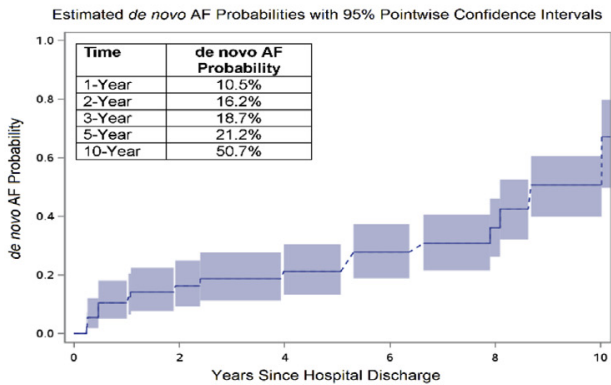

FIGURE E4. Estimates of the de novo AF incidence based on methods for interval-censored data. $A F$, Atrial fibrillation; $M V$, mitral valve. 

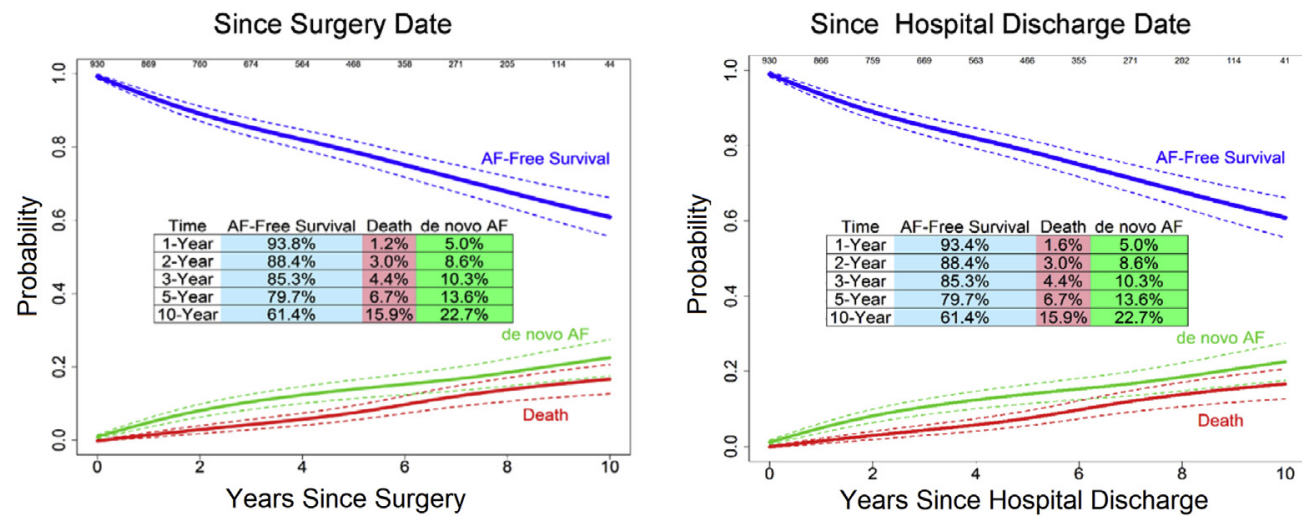

FIGURE E5. Multi-state models summary of probabilities of de novo AF, death, and AF-free survival in the entire cohort. AF, Atrial fibrillation.
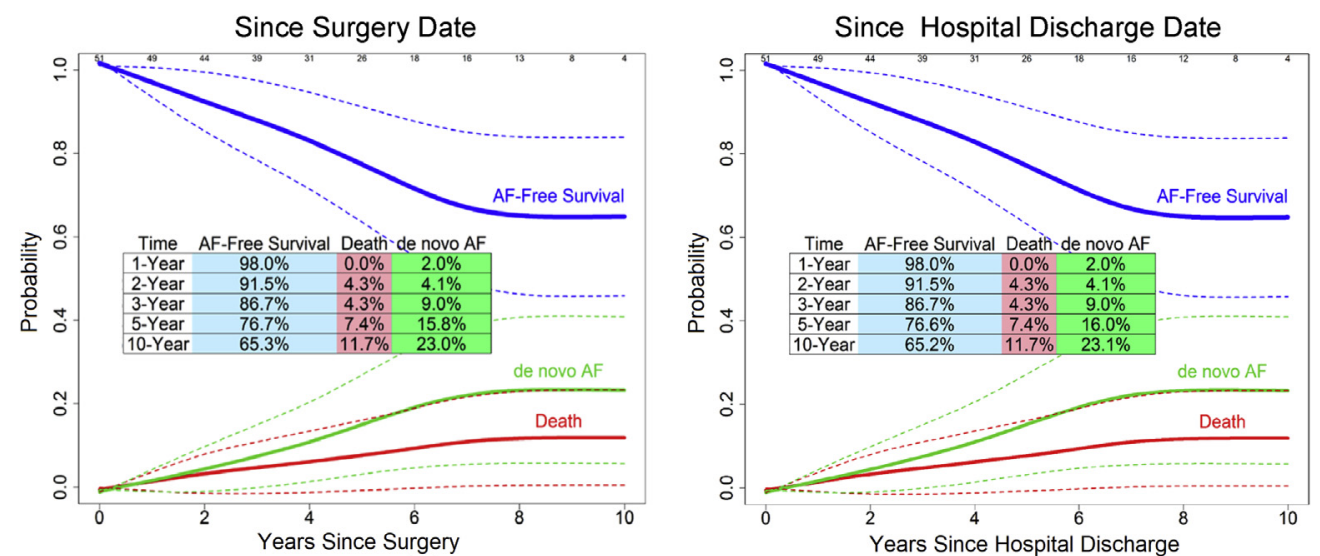

FIGURE E6. Multi-state models summary of probabilities of de novo AF, death, and AF-free survival in rheumatic MV cause. AF, Atrial fibrillation.
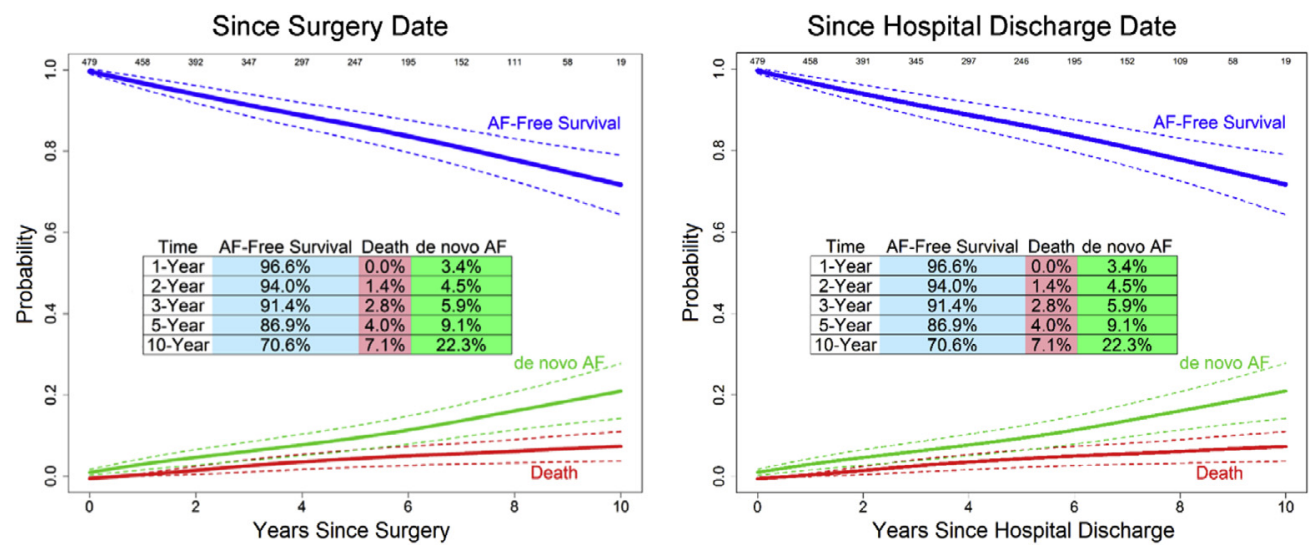

FIGURE E7. Multi-state models summary of probabilities of de novo AF, death, and AF-free survival in degenerative MV cause. AF, Atrial fibrillation. 

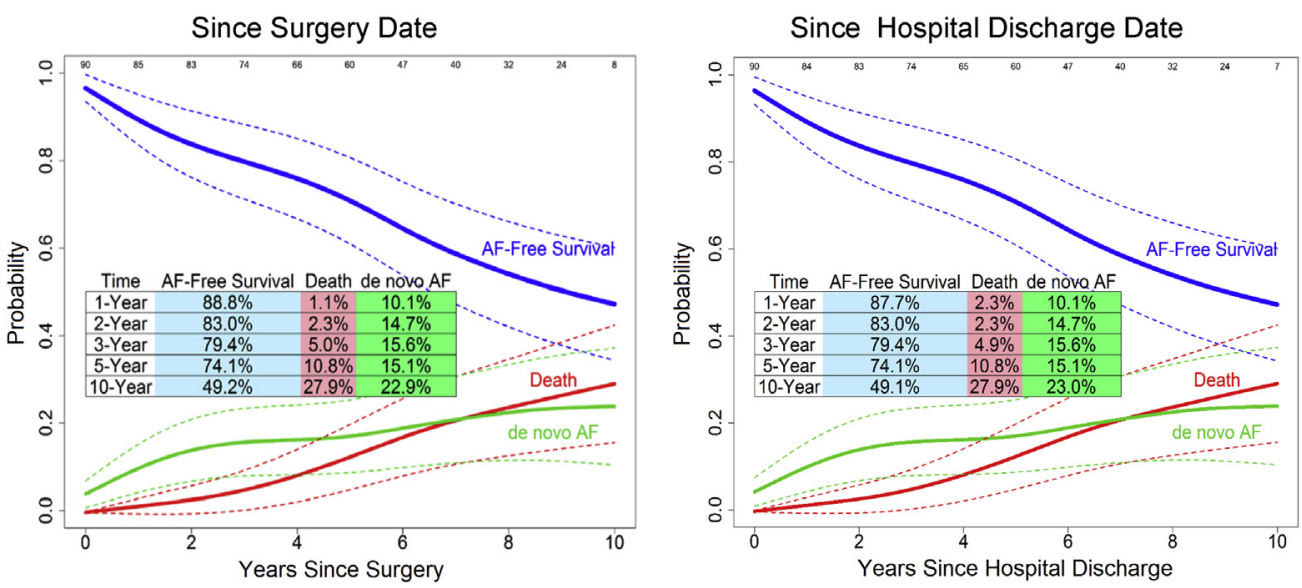

FIGURE E8. Multi-state models summary of probabilities of de novo AF, death, and AF-free survival in ischemic MV cause. AF, Atrial fibrillation.
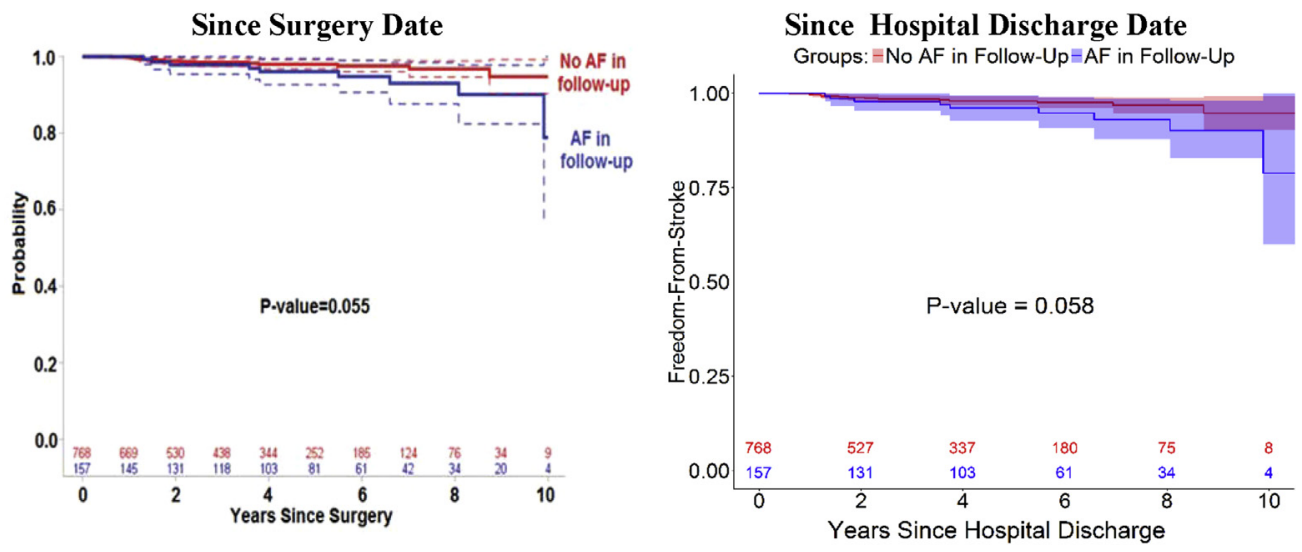

FIGURE E9. Freedom from stroke by AF status in follow-up. $A F$, Atrial fibrillation.
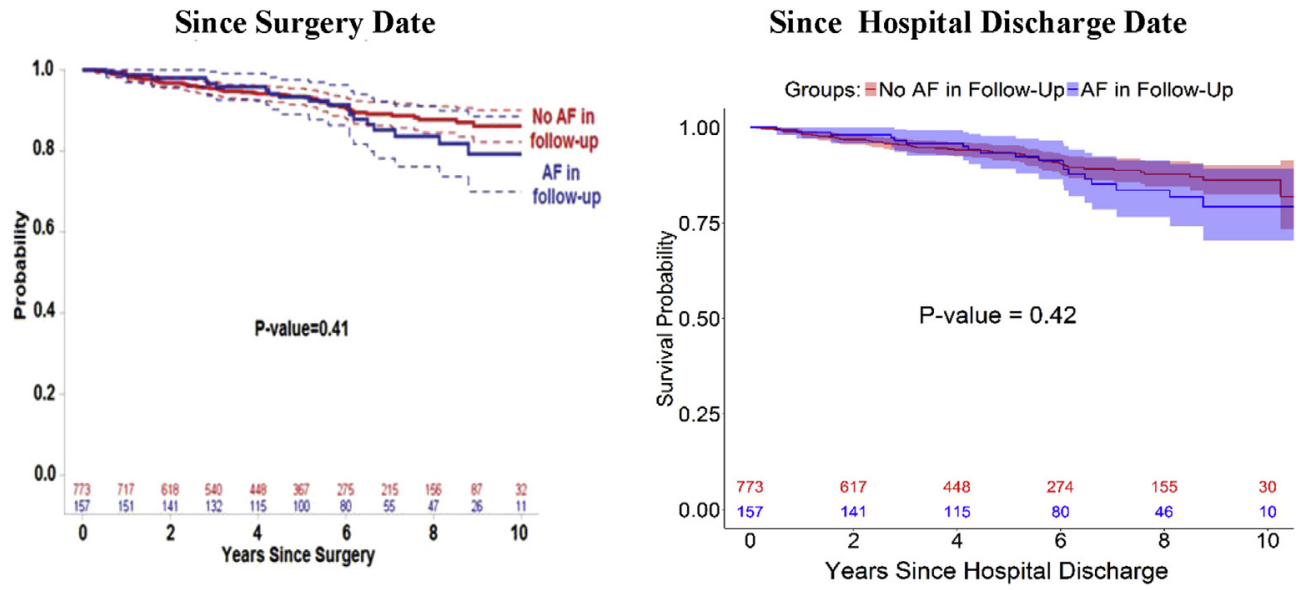

FIGURE E10. Overall survival by AF status in follow-up. $A F$, Atrial fibrillation. 

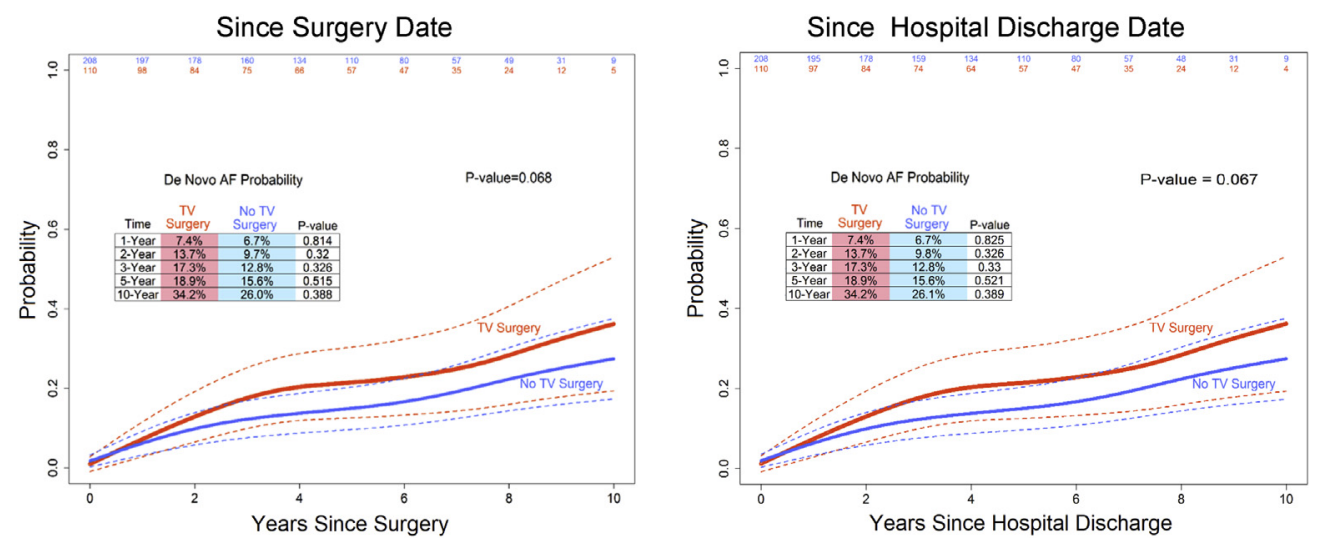

FIGURE E11. Estimated probabilities of developing de novo AF by TV surgery status in PS-matched groups. AF, Atrial fibrillation; $T V$, tricuspid valve.
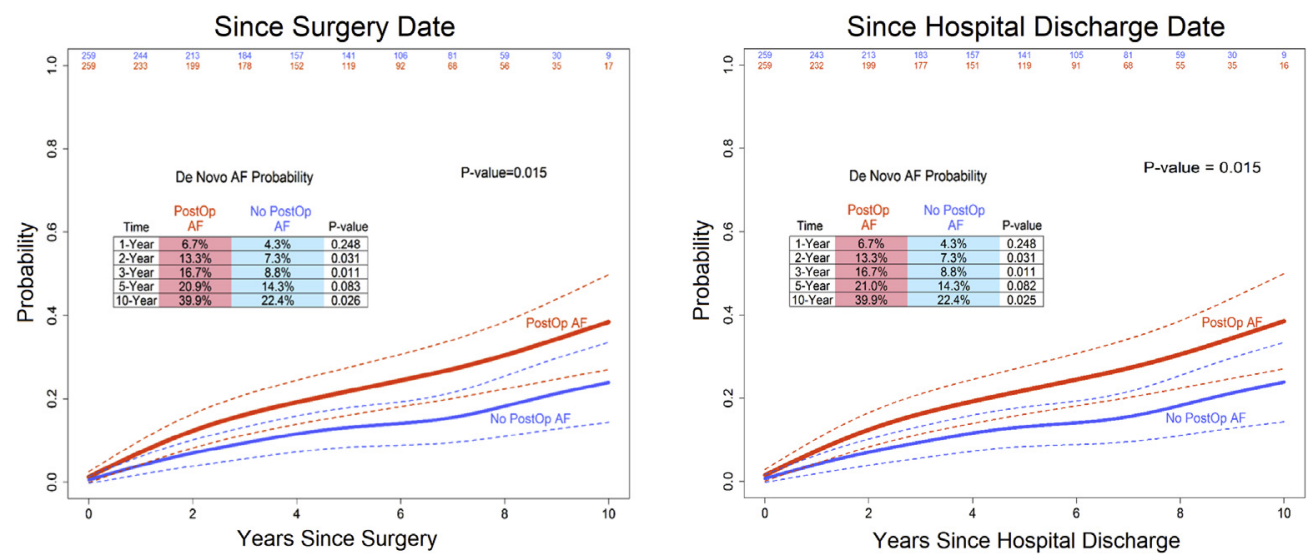

FIGURE E12. Estimated probabilities of developing de novo AF by postoperative AF status in PS-matched groups. AF, Atrial fibrillation. 
TABLE E1. Summary of left atrial diameter, left ventricular ejection fraction, history of congestive heart failure, and mitral valve cause as potential univariate risk factors for developing de novo atrial fibrillation

\begin{tabular}{|c|c|c|c|}
\hline Variable & HR & $95 \% \mathbf{C I}$ & $P$ value \\
\hline Left atrial diameter (continuous) & 1.16 & $(0.95-1.43)$ & .146 \\
\hline \multicolumn{4}{|l|}{ Left atrial diameter (categoric) } \\
\hline$<5 \mathrm{~cm}$ & REF & REF & REF \\
\hline $5-6 \mathrm{~cm}$ & 1.44 & $(0.96-2.17)$ & .08 \\
\hline$\geq 6 \mathrm{~cm}$ & 1.30 & $(0.41-4.10)$ & .65 \\
\hline Left ventricular ejection fraction (continuous) & 1.01 & $(0.98-1.002)$ & .095 \\
\hline \multicolumn{4}{|l|}{ Left ventricular ejection fraction (categoric) } \\
\hline$>45 \%$ & REF & REF & REF \\
\hline $30 \%-45 \%$ & 2.11 & $(1.42-3.13)$ & $<.001$ \\
\hline$\leq 30 \%$ & 1.04 & $(0.60-1.82)$ & .88 \\
\hline History of congestive heart failure & 1.44 & $(1.05-1.99)$ & .024 \\
\hline \multicolumn{4}{|l|}{ MV cause } \\
\hline Degenerative & REF & REF & REF \\
\hline Rheumatic & 1.44 & $(0.68-3.02)$ & .34 \\
\hline Ischemic & 2.31 & $(1.45-3.69)$ & $<.001$ \\
\hline Other & 2.25 & $(1.57-3.21)$ & $<.001$ \\
\hline
\end{tabular}

$H R$, Hazard ratio; $C I$, confidence interval; $M V$, mitral valve. 
TABLE E2. Summary of baseline characteristics in propensity score-matched groups by postoperative atrial fibrillation status

\begin{tabular}{|c|c|c|c|}
\hline Variable & $\begin{array}{c}\text { No postoperative AF } \\
(N=259)\end{array}$ & $\begin{array}{c}\text { Postoperative AF } \\
(\mathrm{N}=259)\end{array}$ & $P$ value \\
\hline Age $(y)$ & $64.7 \pm 11.9$ & $64.4 \pm 11.3$ & .76 \\
\hline Body mass index $\left(\mathrm{kg} / \mathrm{m}^{2}\right)$ & $27.5 \pm 6.0$ & $27.3 \pm 5.3$ & .69 \\
\hline $\mathrm{CHADS}_{2}$ & $1.5 \pm 1.2$ & $1.5 \pm 1.2$ & .91 \\
\hline $\mathrm{CHADS}_{2}$ VASC & $2.6 \pm 1.7$ & $2.5 \pm 1.7$ & .55 \\
\hline Creatinine level, median (Q1, Q3) & $1.0(0.8,1.1)$ & $1.0(0.9,1.2)$ & .35 \\
\hline Ejection fraction, median (Q1, Q3) & $60.0(50.0,65.0)$ & $60.0(50.0,65.0)$ & .84 \\
\hline Left atrial size, median (Q1, Q3) & $4.3(3.7,4.7)$ & $4.3(3.8,4.8)$ & .37 \\
\hline Gender (female) & $110(42 \%)$ & $103(40 \%)$ & .53 \\
\hline Diabetes & $40(15 \%)$ & $40(15 \%)$ & 1.00 \\
\hline Dyslipidemia & $140(54 \%)$ & $145(56 \%)$ & .66 \\
\hline Hypertension & $172(66 \%)$ & $166(64 \%)$ & .58 \\
\hline Chronic lung disease & $36(14 \%)$ & $32(12 \%)$ & .60 \\
\hline Peripheral vascular disease & $15(6 \%)$ & $12(5 \%)$ & .55 \\
\hline Cerebrovascular disease & $21(8 \%)$ & $20(8 \%)$ & .87 \\
\hline Prior stroke & $14(5 \%)$ & $16(6 \%)$ & .71 \\
\hline Previous myocardial infarction & $32(12 \%)$ & $30(12 \%)$ & .79 \\
\hline Prior CABG & $14(5 \%)$ & $17(7 \%)$ & .58 \\
\hline Prior pacemaker & $5(2 \%)$ & $3(1 \%)$ & .48 \\
\hline Congestive heart failure & $88(34 \%)$ & $91(35 \%)$ & .78 \\
\hline NYHA class III or IV & $87(34 \%)$ & $90(35 \%)$ & .78 \\
\hline Coronary artery disease & $98(38 \%)$ & $97(38 \%)$ & .98 \\
\hline Repeat sternotomy & $21(8 \%)$ & $28(11 \%)$ & .29 \\
\hline Elective surgery & $220(85 \%)$ & $221(85 \%)$ & .90 \\
\hline AV stenosis & $34(16 \%)$ & $36(17 \%)$ & .88 \\
\hline MV stenosis & $26(11 \%)$ & $31(13 \%)$ & .52 \\
\hline Preoperative anticoagulants & $18(7 \%)$ & $20(8 \%)$ & .74 \\
\hline Tricuspid regurgitation $>2+$ & $47(19 \%)$ & $60(24 \%)$ & .14 \\
\hline $\begin{array}{l}\text { AV insufficiency } \\
\qquad \begin{aligned} 0 & =\text { None/trivial } \\
1 & =\text { Mild } \\
2 & =\text { Moderate } \\
3 & =\text { Moderate/severe } \\
4 & =\text { Severe }\end{aligned}\end{array}$ & $\begin{array}{c}141(65 \%) \\
50(23 \%) \\
15(7 \%) \\
1(0 \%) \\
10(5 \%)\end{array}$ & $\begin{array}{c}154(69 \%) \\
31(14 \%) \\
23(10 \%) \\
3(1 \%) \\
12(5 \%)\end{array}$ & .10 \\
\hline $\begin{array}{l}\text { MV insufficiency } \\
\qquad \begin{aligned} 0 & =\text { None/trivial } \\
1 & =\text { Mild } \\
2 & =\text { Moderate } \\
3 & =\text { Moderate/severe } \\
4 & =\text { Severe }\end{aligned}\end{array}$ & $\begin{array}{c}3(1 \%) \\
18(7 \%) \\
39(15 \%) \\
23(9 \%) \\
176(68 \%)\end{array}$ & $\begin{array}{c}7(3 \%) \\
17(7 \%) \\
46(18 \%) \\
23(9 \%) \\
164(64 \%)\end{array}$ & .62 \\
\hline Coronary artery bypass & $85(33 \%)$ & $77(30 \%)$ & .45 \\
\hline AV surgery & $61(24 \%)$ & $63(24 \%)$ & .84 \\
\hline TV surgery & $39(15 \%)$ & $38(15 \%)$ & .90 \\
\hline $\begin{array}{l}\text { MV surgery type } \\
\text { Repair } \\
\text { Replacement }\end{array}$ & $\begin{array}{r}194(75 \%) \\
65(25 \%)\end{array}$ & $\begin{array}{r}195(75 \%) \\
64(25 \%)\end{array}$ & .92 \\
\hline
\end{tabular}

$A F$, Atrial fibrillation; $\mathrm{CHADS}_{2}$, congestive heart failure, hypertension, age, diabetes, stroke; $C H A D S_{2} V A S C$, congestive heart failure, hypertension, age, diabetes, stroke, vascular disease; $C A B G$, coronary artery bypass grafting; $N Y H A$, New York Heart Association; $A V$, aortic valve; $M V$, mitral valve; $T V$, tricuspid valve. 
TABLE E3. Summary of baseline characteristics in propensity score-matched groups by tricuspid valve surgery status

\begin{tabular}{|c|c|c|c|}
\hline Variable & No TV surgery $(\mathrm{N}=\mathbf{2 0 8})$ & TV surgery $(\mathrm{N}=110)$ & $P$ value \\
\hline Age & $63.2 \pm 14.2$ & $63.4 \pm 13.7$ & .90 \\
\hline Body mass index $\left(\mathrm{kg} / \mathrm{m}^{2}\right)$ & $26.4 \pm 5.5$ & $26.4 \pm 5.8$ & 1.00 \\
\hline $\mathrm{CHADS}_{2}$ & $1.7 \pm 1.4$ & $1.7 \pm 1.2$ & .96 \\
\hline $\mathrm{CHADS}_{2}$ VASC & $3.0 \pm 2.0$ & $3.0 \pm 1.6$ & .97 \\
\hline Creatinine level, median (Q1, Q3) & $1.0(0.8,1.2)$ & $1.0(0.9,1.3)$ & .49 \\
\hline Ejection fraction, median (Q1, Q3) & $60.0(44.5,65.0)$ & $60.0(45.0,65.0)$ & .45 \\
\hline Left atrial size, median (Q1, Q3) & $4.3(3.8,4.7)$ & $4.3(3.8,4.9)$ & .28 \\
\hline Gender (female) & $112(54 \%)$ & $60(55 \%)$ & .91 \\
\hline Diabetes & $47(23 \%)$ & $24(22 \%)$ & .87 \\
\hline Dyslipidemia & $108(52 \%)$ & $56(51 \%)$ & .86 \\
\hline Hypertension & $115(55 \%)$ & $61(55 \%)$ & .98 \\
\hline Chronic lung disease & $24(12 \%)$ & $11(10 \%)$ & .68 \\
\hline Peripheral vascular disease & $13(6 \%)$ & $6(5 \%)$ & .78 \\
\hline Cerebrovascular disease & $23(11 \%)$ & $11(10 \%)$ & .77 \\
\hline Prior stroke & $15(7 \%)$ & $8(7 \%)$ & .98 \\
\hline Previous myocardial infarction & $38(18 \%)$ & $17(15 \%)$ & .53 \\
\hline Prior coronary artery bypass graft & $23(11 \%)$ & $12(11 \%)$ & .97 \\
\hline Prior pacemaker & $8(4 \%)$ & $7(6 \%)$ & .31 \\
\hline Congestive heart failure & $103(50 \%)$ & $54(49 \%)$ & .94 \\
\hline NYHA class III or IV & $95(46 \%)$ & $50(45 \%)$ & .97 \\
\hline Coronary artery disease & $89(45 \%)$ & $44(41 \%)$ & .54 \\
\hline Repeat sternotomy & $41(20 \%)$ & $20(18 \%)$ & .74 \\
\hline Elective surgery & $166(80 \%)$ & $87(79 \%)$ & .88 \\
\hline AV stenosis & $24(13 \%)$ & $19(21 \%)$ & .12 \\
\hline MV stenosis & $32(16 \%)$ & $19(19 \%)$ & .55 \\
\hline Preoperative anticoagulants & $23(11 \%)$ & $14(13 \%)$ & .66 \\
\hline $\mathrm{TR}>2+$ & $24(12 \%)$ & $81(80 \%)$ & $<.001$ \\
\hline $\begin{array}{l}\text { AV insufficiency } \\
\begin{aligned} 0 & =\text { None/trivial } \\
1 & =\text { Mild } \\
2 & =\text { Moderate } \\
3 & =\text { Moderate/severe } \\
4 & =\text { Severe }\end{aligned}\end{array}$ & $\begin{array}{c}120(66 \%) \\
35(19 \%) \\
15(8 \%) \\
3(2 \%) \\
9(5 \%)\end{array}$ & $\begin{array}{c}60(62 \%) \\
19(20 \%) \\
8(8 \%) \\
1(1 \%) \\
9(9 \%)\end{array}$ & .70 \\
\hline $\begin{array}{l}\text { MV insufficiency } \\
\qquad \begin{aligned} 0 & =\text { None/trivial } \\
1 & =\text { Mild } \\
2 & =\text { Moderate } \\
3 & =\text { Moderate/severe } \\
4 & =\text { Severe }\end{aligned}\end{array}$ & $\begin{array}{c}9(4 \%) \\
16(8 \%) \\
37(18 \%) \\
17(8 \%) \\
128(62 \%)\end{array}$ & $\begin{array}{c}4(4 \%) \\
9(8 \%) \\
17(15 \%) \\
12(11 \%) \\
68(62 \%)\end{array}$ & .92 \\
\hline Coronary artery bypass grafting & $71(34 \%)$ & $34(31 \%)$ & .56 \\
\hline AV surgery & $42(20 \%)$ & $24(22 \%)$ & .73 \\
\hline $\begin{array}{l}\text { MV surgery type } \\
\text { Repair } \\
\text { Replacement }\end{array}$ & $\begin{array}{r}140(67 \%) \\
68(33 \%)\end{array}$ & $\begin{array}{l}72(65 \%) \\
38(35 \%)\end{array}$ & .74 \\
\hline
\end{tabular}

$T V$, Tricuspid valve; $\mathrm{CHADS}_{2}$, congestive heart failure, hypertension, age, diabetes, stroke; $\mathrm{CHADS}_{2} V A S C$, congestive heart failure, hypertension, age, diabetes, stroke, vascular disease; $N Y H A$, New York Heart Association; $A V$, aortic valve; $M V$, mitral valve; $T R$, tricuspid regurgitation. 
TABLE E4. Summary of significant univariate risk factors for developing de novo atrial fibrillation

\begin{tabular}{|c|c|c|c|c|}
\hline \multirow[b]{2}{*}{ Variable } & \multicolumn{2}{|c|}{ Models for time since surgery date } & \multicolumn{2}{|c|}{ Models for time since hospital discharge date } \\
\hline & HR $(95 \%$ CI) & $P$ value & HR $(95 \%$ CI $)$ & $P$ value \\
\hline Age, y & $1.04(1.03-1.05)$ & $<.001$ & $1.04(1.03-1.05)$ & $<.001$ \\
\hline Diabetes & $1.60(1.07-2.41)$ & .021 & $1.61(1.08-2.41)$ & .028 \\
\hline Hypercholesterolemia & $1.43(1.04-1.96)$ & .027 & $1.43(1.04-1.96)$ & .027 \\
\hline Hypertension & $1.56(1.13-2.16)$ & .007 & $1.56(1.13-2.16)$ & .006 \\
\hline $\begin{array}{l}\text { Prior cerebrovascular } \\
\text { accident }\end{array}$ & $1.74(1.02-2.96)$ & .043 & $1.74(1.03-2.98)$ & .056 \\
\hline Prior coronary artery bypass & $1.94(1.12-3.35)$ & .019 & $1.94(1.12-3.36)$ & .031 \\
\hline Prior pacemaker & $3.10(1.63-5.90)$ & $<.001$ & $3.10(1.63-5.91)$ & .003 \\
\hline Congestive heart failure & $1.44(1.05-1.99)$ & .024 & $1.45(1.05-1.99)$ & .025 \\
\hline Coronary artery disease & $1.79(1.30-2.46)$ & $<.001$ & $1.79(1.30-2.46)$ & $<.001$ \\
\hline Repeat sternotomy & $1.84(1.21-2.81)$ & .005 & $1.85(1.21-2.82)$ & .008 \\
\hline Aortic stenosis & $1.90(1.25-2.87)$ & .002 & $1.90(1.26-2.88)$ & .005 \\
\hline Mitral stenosis & $1.70(1.10-2.65)$ & .018 & $1.71(1.10-2.65)$ & .025 \\
\hline Coronary artery bypass & $1.66(1.20-2.30)$ & .003 & $1.66(1.20-2.30)$ & .003 \\
\hline AV surgery & $1.89(1.35-2.65)$ & $<.001$ & $1.89(1.35-2.66)$ & $<.001$ \\
\hline TV surgery & $2.34(1.62-3.40)$ & $<.001$ & $2.35(1.62-3.41)$ & $<.001$ \\
\hline MV replacement (vs repair) & $1.74(1.24-2.46)$ & .002 & $1.75(1.24-2.47)$ & .002 \\
\hline \multicolumn{5}{|l|}{ TV regurgitation } \\
\hline None/trivial & REF & REF & REF & REF \\
\hline Mild & $1.33(0.92-1.94)$ & .133 & $1.33(0.91-1.94)$ & .135 \\
\hline Moderate & $1.86(1.15-3.01)$ & .011 & $1.86(1.15-3.01)$ & .012 \\
\hline Moderate/severe & $1.67(0.61-4.62)$ & .319 & $1.67(0.61-4.61)$ & .321 \\
\hline Severe & $3.52(1.80-6.89)$ & $<.001$ & $3.55(1.82-6.95)$ & $<.001$ \\
\hline TV regurgitation $\geq 2+$ & $1.87(1.29-2.72)$ & .001 & $1.87(1.29-2.72)$ & .002 \\
\hline \multicolumn{5}{|l|}{$\mathrm{CHADS}_{2}$ score } \\
\hline 0 & REF & REF & REF & REF \\
\hline 1 & $1.98(1.23-3.18)$ & .005 & $1.99(1.24-3.19)$ & .004 \\
\hline 2 & $2.78(1.69-4.57)$ & $<.001$ & $2.78(1.69-4.57)$ & $<.001$ \\
\hline 3 & $2.48(1.39-4.44)$ & .002 & $2.49(1.40-4.46)$ & .002 \\
\hline 4 & $3.80(1.77-8.15)$ & $<.001$ & $3.83(1.78-8.21)$ & $<.001$ \\
\hline 5 & $4.66(1.87-11.13)$ & $<.001$ & $4.57(1.87-11.17)$ & $<.001$ \\
\hline \multicolumn{5}{|l|}{ MV cause } \\
\hline Degenerative & REF & REF & REF & REF \\
\hline Rheumatic & $1.44(0.68-3.02)$ & .34 & $1.44(0.68-3.02)$ & .34 \\
\hline Ischemic & $2.31(1.45-3.69)$ & $<.001$ & $2.32(1.45-3.69)$ & $<.001$ \\
\hline Other & $2.25(1.57-3.21)$ & $<.001$ & $2.26(1.58-3.23)$ & $<.001$ \\
\hline
\end{tabular}

$H R$, Hazard ratio; $C I$, confidence interval; $A V$, aortic valve; $T V$, tricuspid valve; $M V$, mitral valve; $C H A D S_{2}$, congestive heart failure, hypertension, age, diabetes and stroke. 
TABLE E5. Summary of multivariable risk factors for developing de novo atrial fibrillation in follow-up

\begin{tabular}{|c|c|c|c|c|}
\hline \multirow[b]{2}{*}{ Variable } & \multicolumn{2}{|c|}{ Models for time since surgery date } & \multicolumn{2}{|c|}{ Models for time since hospital discharge date } \\
\hline & HR $(95 \%$ CI $)$ & $P$ value & HR $(95 \%$ CI) & $P$ value \\
\hline Age & $1.03(1.02-1.05)$ & $<.001$ & $1.03(1.02-1.05)$ & $<.001$ \\
\hline Prior pacemaker & $1.75(0.88-3.48)$ & .11 & $1.74(0.88-3.47)$ & .11 \\
\hline Repeat sternotomy & $1.29(0.82-2.02)$ & .28 & $1.29(0.82-2.03)$ & .27 \\
\hline AV surgery & $1.37(0.93-2.03)$ & .108 & $1.37(0.93-2.03)$ & .109 \\
\hline TV surgery & $1.73(1.17-2.56)$ & .005 & $1.74(1.18-2.57)$ & .005 \\
\hline \multicolumn{5}{|l|}{ MV cause } \\
\hline Degenerative & REF & REF & REF & REF \\
\hline Rheumatic & $0.98(0.45-2.16)$ & .96 & $0.98(0.45-2.16)$ & .97 \\
\hline Ischemic & $1.48(0.90-2.42)$ & .12 & $1.48(0.91-2.43)$ & .12 \\
\hline Other & $1.68(1.11-2.52)$ & .013 & $1.68(1.12-2.53)$ & .013 \\
\hline
\end{tabular}

$H R$, Hazard ratio; $C I$, confidence interval; $A V$, aortic valve; $T V$, tricuspid valve; $M V$, mitral valve. 